\title{
Historical Development of the Windmill
}

Dennis G. Shepherd

Cornell University

Ithaca, New York

Prepared for

National Aeronautics and Space Administration

Lewis Research Center

under Contract NAS3-25266

Work performed for

U.S. Department of Energy

Wind/Hydro/Ocean Technologies Division

and

Solar Energy Research Institute

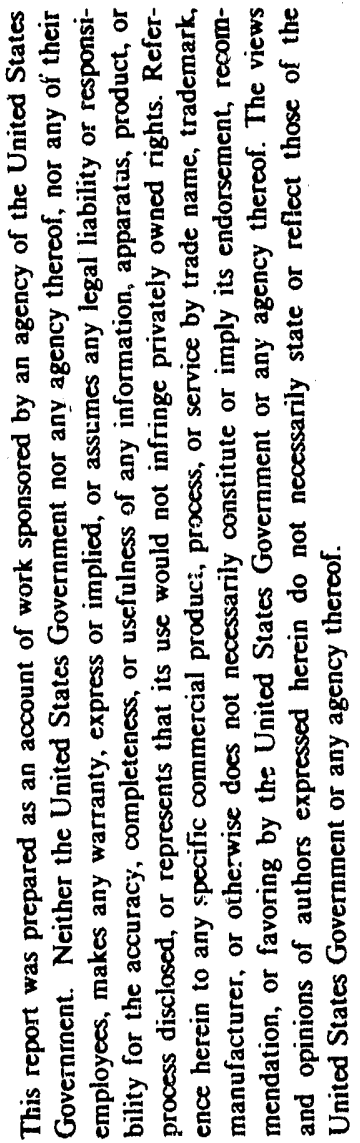

Solar Technology Information Program

under Interagency Agreement DE-AI01-76ET-20320

\section{N/SA}

National Aeronautics and

Space Administration

Office of Management

Scientific and Technical

Information Division 
The text of this report is planned to appear as a chapter in a forthcoming book entitled Wind Turbine Technology. This is a joint project of the U.S. Department of Energy and the American Society of Mechanical Engineers, in which the NASA Lewis Research Center is responsible for technical editing and management. Production of the final text is under the sponsorship and direction of DOE's Solar Technical Information Programs Office. Book publication will be by the ASME. 


\title{
Historical Development of the Windmill
}

\author{
Dennis G. Shepherd \\ Professor of Mechanical and Aerospace Engineering \\ Cornell University \\ Ithaca, New York
}

\section{Introduction}

The wind turbine has had a singular history amrng prime movers. Its genesis is lost in antiquity, but its existence as a provider of useful mechanical power for the last thousand years has been authoritatively established. Although there are a few earlier mentions in the literature, these are generally not acceptable for recognition as historical fact by most professional historians of technology. The windmill, which once flourished along with the water wheel as one of the two prime movers based on the kinetic energy of natural sources, reached its apogee of utility in the seventeenth and eighteenth centuries. Its use then began to decline, as prime movers based on thermal energy from the combustion of fuel took precedence. Steam engines, steam turbines, and oil and gas engines provided more powerful and more compact machines, adaptable to a multitude of uses other than just the grinding of grain and the pumping of water. These new heat engines also were continuously available rather than subject to the vagaries of nature, and they could be located at the job site rather than requiring that the job be brought to them. 
Nevertheless, the windmill persisted through the industrial revolution; it even continued to supply essential service into the twenticth century in sparsely populated areas where relatively small amounts of scattered power were required, and constant availability was not essential. This was particularly true in the United States and in other countries having vast land masses, such as the USSR, Australia, and the Argentine. In the industrialized regions of the world, where greater population densities and increasing manufacturing enterprises were the rule, the windmill was becoming moribund by the end of the first third of the twentieth century.

Wind machines, however, were revived by the emergence and proliferation of two major technologies: the rapid spread of electricity as a versatile transducer of energy between the prime mover and the job, and the burgeoning of the engineering science of aerodynamics, which was occasioned by the development of the airplane. At the end of the last century, in the years from 1888 to 1900 , experiments began in which windmills were used to generate electricity, both in the United States and in Denmark, which has no fossil fuels of its own.

The history of wind power in Denmark provides a salutary example of how socioeconomic conditions can both inhibit a technology's gradual but continuous development and rescue it from an apparently endless decline, when politics or economics intervene. From 1900 to 1910, many Danish wind-driven electricity plants were in use, particularly for agriculture, but diesel engines were beginning to give them some stiff competition by 1910 to 1914 because of their convenience and economy [Juul 1956, 1964]. However, during World War I, oil supplies to the country were virtually shut off and wind power was resurreited; many $20-1035-\mathrm{kW}$ plants were built at that time. After the war, electrification took place throughout the country, and once more the windmill languished. In 1939, World War II caused another cut-off in fuel supplies, and wind power was once more called upon to the fullest extent possible. After the hostilities ended, further rapid, extensive clectrification took place, but this time the utility of wind power was not discounted; instead, a research program was begun to consider it as a supplement to the large, central plants.

These compelling reminders of the perils of relying on transported energy sources, logether with a degree of awareness of the eventual dissipation of these sources, prompted some of the development of windmills into wind turbines. In the period after 1945, there were developments not only in Denmark, but in France, Germany, and Britain, as well. These developments might have been stimulated by the 1.25-MW Smith-Putnam turbine in the United States, which operated during the war. All these ventures enjoyed some degree of technical success, but that was not sustained, because they were not considered to be cost-effective. However, they did provide a useful starting point for the renaissance of wind power in the carly 1970s, which was prnvoked by the international oil crisis of 1972.

In contrast to the uneven history of the windmill, the water mill has enjoyed $20^{\prime} 00$ years of slow but continuous development up to this very day. Built in multimegawatt sizes, it achieves the highest efficiencies of any prime mover. The water mill has changed, in its general physical characteristics, considerably over the centuries; the windmill, bu' little (in detail, yes, but not in form). In fact, if a European miller of the thirteenth century were given the opportunity to observe the operations floor of a modern hydroelectric plant, he would be utterly confounded. On being taken to see a wind power station in California, however, he might immediately express his delight in seeing so many wind. mills in use, although he might also inquire as to why so many of them had lost one or two sails.

This brief review might serve to place the evolution of the windmill in its general context. Now, however, we shall go back in time to its origins and its early development, exploring its mechanical design and some problems that were solved by early engineers and some that were not. Bui first, it is desirable to establish an important feature of nomenclature, to avoid confusion in discussing the literature of the past and of the present. 
Notice that we have used both the terms windmill and wind surbine in the preceding overview. Modern technology has firmly and rightly established the wind turbine as the prime mover of a wind machine capable of being harnessed for a number of different applications, none of which are concerned with the milling of grain or other substances (at least in industrialized countries), together with the various other pieces of apparatus necessary for a complete power plant: transmission, nacelle, tower, load (generator, pump), control gear, and so forth. The wind turbine is also described as a wind energy conversion system (WECS) or, if used to produce electric power, as a wind turbine generator (WTG).

However, up to recent times the term windmill was used for the whole system, whatever its duty, be it generating electricity, pumping water, sawing wood, or, as we shall see a litlle later, pumping air for an organ. It seems that in nearly all previous writings, windmill is used, whether it is directed toward technological, historical, or simply antiquarian aspects (or combinations of them). Since this chapter is concerned with past events, it is convenient and has a certain logic in it to retain this term in its historic sense, using such words as wheel, rotor, or blades to refer to whit we now call the turbine itself.

The adjectives horizontal or vertical atlached to the two major classes of wind machine are a potential source of misunderstanding. In modern terminology, they refer to the geometrical aspect of the driving shaft on which the rotor (turbine) is mounted. For example, an oldtime wooden machine with four sails (a type typified by the term Dutch windmill) is now called a horizontal-axis wind turbine (HAWT). Past usage terms it a vertical windmill, because the path of a point on a moving blade lies in a vertical plane. A machine built like a carousel with a central vertical axis and a number of straight or bent vanes arranged in a direction more or less parallel to the shaft is today called a verticalaxis wind turbine (VAWT) but in past times a horizontal windmill. This typology is emphasized here hacause the new and old usages are diarnetrically opposed. To avoid confusion, modern terminology will be followed. The terms horizontal-axis windmill and vertical-axis windmill will be used here, although molinologists continue to study vertical and horizontal windmills.

The International Molinological Society (TIMS) was formed following a meeting in Portugal in 1965 of savants and others interested in windmills. The word molinology was introduced and officially adopted at that time to define the field of studies concerned with windmills, water mills, and animal-powered mills. The term is derived from the root molino found in differing national forms in many countries of the Western Hemisphere; it can be combined with such Greek suffixes as -ology, -graph, -phile, etc. It was proposed to the philological authorities of every country for adoption into their vocabularies and dictionaries, but it does not appear in the 1986 updated version of Webster's New International Dictionary nor in the 1976 supplement of the Oxford English Dictionary. Since the first gathering, meetings of TIMS have been held in 1969 (Denmark), 1973 (The Necherlands), 1977 (England), and 1982 (France). The transactions of the first meeting were not published until 1977; those of the later meetings were issued in 1971, 1975, 1979, and 1984, respectively. These volumes are a most interesting and valuable source of current matters connected with the history, cataloging, and preservation of windmills. The assistance of a professional librarian may be necessary to locate copies of these volumes, because they are cataloged under different call numbers and each is issued by a different publisher, generally from the host country for the meeting.

This chapter is aimed toward engineers and technology-minded readers and not toward molinological scholars. Hence, the author has tried to steer a middle course with respect to quoted sources by endeavoring to give proper credit for specific material without overloading the text with references of interest only to the specialist. In addition, he has leaned heavily on many of these sources for the general information as well as the particular material contained in them, and he acknowledges this debt with gratitude. 


\section{Ancient Times}

The carliest mentions of the use of wind power come from the East: India, Tibet, Afghanistan, Persia. Ancient manuscripts, however, have often suffered from mistranslations, revisions, and interpolations by other hands over the centuries. In some, even diagrams were changed to suit the whims of revisionists, and there are instances of forgeries. Drachman [1961], Needham [1965], Vowles [1930], and White [1962] all cite examples of these aberrations. Marie Boas provides a good illustration of the treatment a manuscript can undergo in her detailed monograph, "Hero's Pneumatica - A Study of its Transmission and Influence" [1949].

Mentioning the Boas monograph is apposite here because of the well-known ascription of the invention of the windmill to Heron (a variant of Hero) of Alexandria, by virtue of his account of it as one of the many devices in his Pneumatica of 2000 years ago. This ascription is now discounted by most authorities in varying degrees, ranging from outright rejection, through wistful reluctance to relinquish the idea, to acceptance as only a toy. There is difficulty with respect to the provenance of a sketch in the Pneumatica and some disagreement as to the exact meaning of certain key words. This story is reviewed here because it is a classic example of the difficulty of making a positive attribution from an ancient manuscript. Was Heron really the inventor of the windmill as a practical prime mover, and was his invention the inspiration for those that followed, even though centuries elapsed between the birth of the idea and its fulfillment?

The exact dates of Heron's birth and death are not known. Surmises lie between the second century B.C. and the third century A.D.; some time in the first century A.D. is perhaps the most probable. His Pneumatica (best known to many as the source of the reaction stcam turbine) consists of descriptions of various ingenious apparatuses that operate on the basis of air or water; some of them are what we would now call toys or even "magic" devices. He himself said that he added some of his own inventions, but he did not say which ones thicy were. The book was known and referred to in medieval times, but many transcripts and translations into Latin or Greek have been lost either in whole or in part. An English translation was provided by Bennet Woodcroft [1851] and a German one by Wilhelm Schmidt [1899]. The latter contains the original Greek wording side by side with the German, and it is generally accepted as a standard text.

The opening sentence of the relevant chapter in the Pneumatica is given by Woodcroft as "the construction of an organ from which when the wind blows the sound of a flute shall be produced." Schmidt provides essentially the same translation in his German version. Both contain diagrams [Figure 1-1(a) and (b)] showing a shaft with blades at one end and four pegs at the other, the pegs intermittently striking a lever rod which then lifts a piston contained in a cylinder. Between lifts, the piston falls in the cylinder of its own weight, resulting in air being pumped to a musical organ. Although both drawings are based on the description in the text, each suits the translator's own imagination: Woodcroft presents a horizontal-axis rotor having four sails, a type unknown until the twelfth century, and Schmidt shows a water-mill type of rotor, again from a much later era. But Schmidt does discuss in his introduction a much cruder version of the rotor illustrated in Figure 1-1(c). According to Drachman [1961], who has made a detailed reassessment in recent years, this is as close to the original sketch as we are likely to get. Vowles also discusses the Pneumatica puzzle [1930] and shows four examples of transmogrified images from various later manuscripts that help to compound the confusion.

In addition to the difficulty we have with the drawings of Heron's device, the exact meaning of some of the words leaves us in doubt. Two prime examples are the word anemurion, meaning a windmill or only a weathervane, and whether Heron uses the word organon to mean a musical organ or just as a generic term, as we might speak of an organ of the body. There are design problems as well, such as turning the device into the wind (stated as being possible in the text) and the peg-driven tripping and return motion (in lieu of a crank) requiring a very rapid oscillating movement of the piston. Neither of these 
(a)

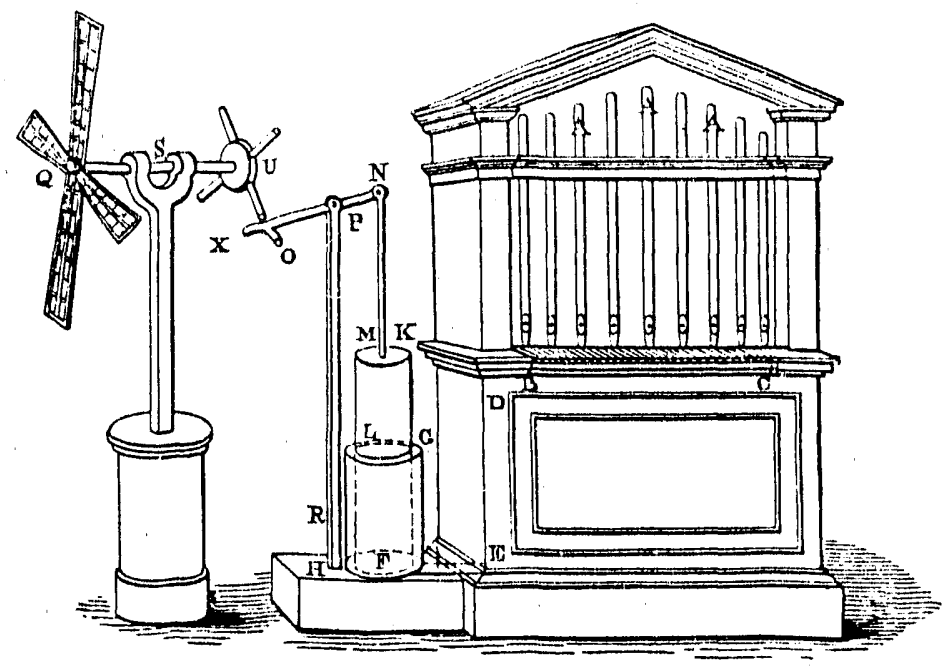

(b)

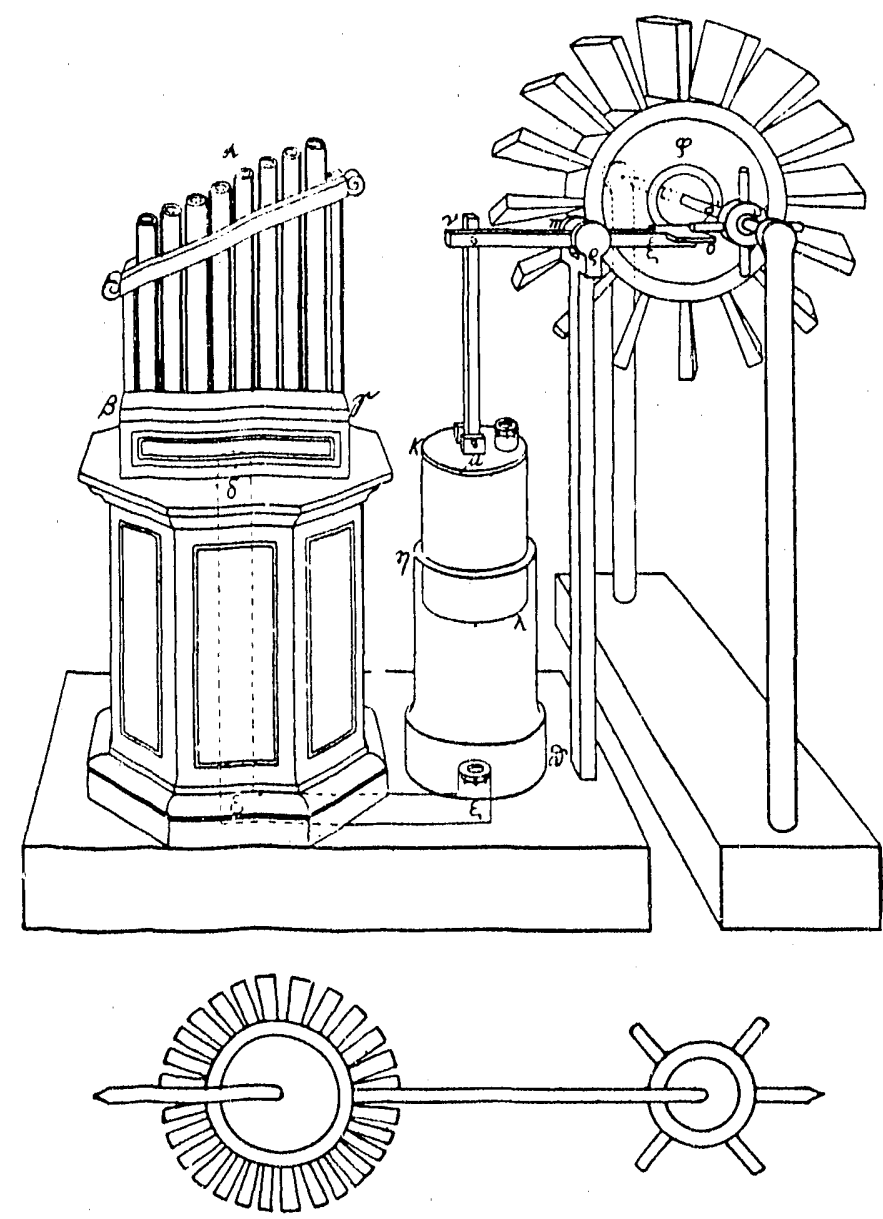

Figure 1-1. Some concepts of the windmill-like device, or organ, described by Heron of Alexandria in his Pneumatica, possibly in the first century A.D. (a) A Dutch-style rotor driving a disk with four pegs that repeatedly raise the piston in an air pump [Woodcroft 1851]. (b) The device with a watermill type of rotor [Schmidt 1899]. (c) Heron's sketch of the drive, according to Schmidt [1899]. Note the needlebearing ends of the shaft. 
operations scems to be possible except in a very small model that could be moved by hand, and one having a very light piston. So perhaps the device was meant to be a toy and not an invention to be taken seriously as a useful working machine.

If the inventor of the windmill was not Heron of Alexandria, then who, and where? This we cannot answer, nor can we think it reasonable that we ever will. Perhaps there was no one person who ever left such a clear record as Heron's, however suspicious we are of his particular account. Instead, perhaps a number of small steps, taken by trial and error in a number of different places over the years, eventually were diffused to yield a working machine with no specific birth to record. Vowles points out at some length that, despite the lack of any lirect evidence, the windmill might have been known in Graeco-Roman times by other than "the not too clear example from Heron's work" [1930]. Thus, we are not justified in rejecting the possibility of its invention in that era.

The first part of the thousand-year medieval period, from the end of the Roman Empire to the Renaissance, is called the Dark Ages, although perhaps they were not quite so dark as they were once thought to be. The Greek culture had spread to many places beyond the mainland (including Alexandria, of course), and schools of learning were established throughout the Near and Middle East, Palestine, Syria, Anatolia, Mcsopotamia, and Persia, to call them by their older names. This region became part of Islam by the Mohammedan conquest in the seventh century, and so the Greek heritage became available to the whole of Islam. Many Greek texts were translated into Arabic and thus had a much wider, and less academic, audience. However, although these are known to have included the Pneumatica, the time of its appearance is problematical and may have been as early as the ninth century [Vowles 1930]. Thus, Heron's work might have stimulated the use of wind power in the Islamic world, but there is no hard evidence to substantiate that. Nearly all the stories and the records we have from between the first and the twelf th centuries come from the Near East and Central Asia, and so those regions of the world are generally considered to be the birthplace of the windmill.

\section{The Vertical-Axis Persian Windmill}

There have been suggestions that the Tibetan prayer wheel was the inspiration for the windmill, but although this is a possibility, the provenance of the prayer wheel itself is very doubtful. The next chronological reference to the windmill that we have refers to the seventh century, but the text itself appeared at least 200 years later. The story was well known and was repeated by several writers in more than one version. The first mention is by A Ti al-Tabari (A.D. 834-927).* According to Needham [1965], the Caliph Omar was murdered in the Islamic capital of Medina in A.D. 644 by a captured Persian technician/ slave, $A \overline{b u}$ Lu'lu'a, who was bitter about the high taxes; he also claimed to be able to build mills driven by the wind. This was repeated by the geographer Ali al-Mas'udi (c. A.D. 956), apparently in a slightly variant form in which the Caliph asked the craftsman if he had boasied ahout being able to build a mill driven by the wind, to which he received the reply, "By God, I will build this mill of which the World will talk" [Wulff 1966]. Because it was orally transmitted over many years, and there is no record of it by any writer around the time of Omar's death, the incident can be used only to lend some plausibility to the possible existence of the windmill in the Islamic world in the middle of the seventh century.

*Authors differ frequently as to spelling and diacritical marks in Arabian names. Here, Needham's usage has been followed for consistency, and because he introduces all such names given in this text. 
We now come to the first accepted establishment of the use of windmills; this was in the tenth century in Persia. It is documented by reliable writers and reinforced by ancient drawings that correspond to the remains of old mills anc to modern ones still in use. The region is Sistan in eastern Persia, which bordered on Afghanistan; al-Mas' ùdi describes it as "the land of winds and sand. There the wind drives mills and raises water from the streams, whereby gardens are irrigated. There is in the world, and God alone knows it, no place where more frequent use is made of the winds." Al-Istakhri, also of about A.D. 950, provides a similar description as well as an interesting account of how the inhabitants coped with a shifting dune. They enclosed it in a high fence with a door in a lower part that allowed the wind to blow the sand away from the fence, which adds credibility to their skill in mastering the windmill. The wind of Sistan is famous, or rather notorious, as it is said to reach $45 \mathrm{~m} / \mathrm{s}(100 \mathrm{mph})$ and to blow at gale force with little respite for four months in late spring and early summer [Bellew 1874; Hedin 1910].

Some three hundred years later we have more confirmation from the geographer alQazwini (A.D. 1203-1283), who wrote, "There the wind is never still, so in reliance on it mills are erected; they do all their corn grinding with these mills, it is a hot land and has mills which depend on the utilization of the wind" [Wulff 1966]. About A.D. 1300, we have the report of al-Dimashqi (A.D. 1256-1326), a Syrian cosmographer who provided a detailed description and a drawing, shown as Figure 1-2. The two-storied, walled structure had millstones at the top and a rotor at the bottom, the latter consisting of a spoked reel

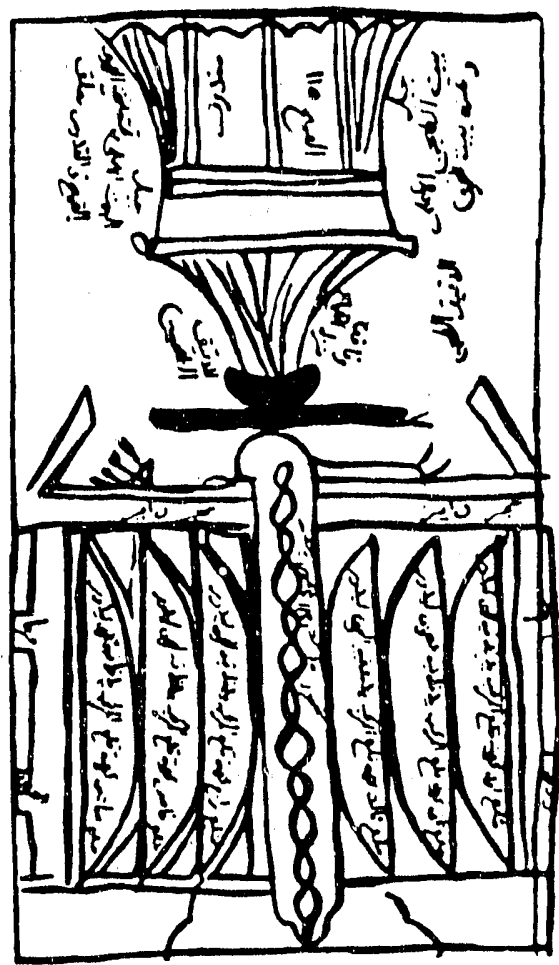

Figure 1-2. A Persian vertical-axis windmill in sistan, according to al-Dimashqi, c. A.D. 1300 [Wulff 1966]. The grinding stones are above the rotor with its bellying cloth sails. The walls have openings to let the wind in and out. (Reprinted by permission of MIT Press; (1966, MIT Press) with 6 to 12 upright ribs, each covered with cloth to form separate sails like longitudina: fins on a heat-exchanger tube. The sketch shows the bellying of the cloth coverings as they catch the wind and push the reel around. Each wall had an offset opening the height of the rotor, with its perimeter beveled to decrease the free area through the thickness of the wall and hence accelerate the wind from any direction.

Windmills of this basic type were still in use in Sistan in 1963, when Wulff saw 50 of them operating in the town of Neh; they might still be used today. They throw much light on what al-Dimashqi saw, so we will skip a few centuries in this generally chronological presentation and condense Wulff's description of the mills in Neh.

The construction is shown in Figure 1-3(a). The rotor is about $5.5 \mathrm{~m}$ high and $4.3 \mathrm{~m}$ in diameter, enclosed in side walls about $6.5 \mathrm{~m}$ high with a half-wall that leaves a $2.2-\mathrm{m}$-wide opening facing north, the main wind direction. The central wooden shaft is about $43 \mathrm{~cm}$ in diameter. Its bottom end, which extends downward into the mill room, contains a steel thrust pin that rests on a wooden thrust block in a cavity lined with a tallow-soaked lubrication pad of many layers of cioth. The upper millstone is atiached to this steel pin, and the lower stone rests on a brick structure. These stones are about $2 \mathrm{~m}$ in dianeter.

The rotor shaft supports five tiers of spokes, with eight spokes in each tier. Each sail is romposed of several long bundles of reeds pressed against the end of the spokes by tie bars and is 

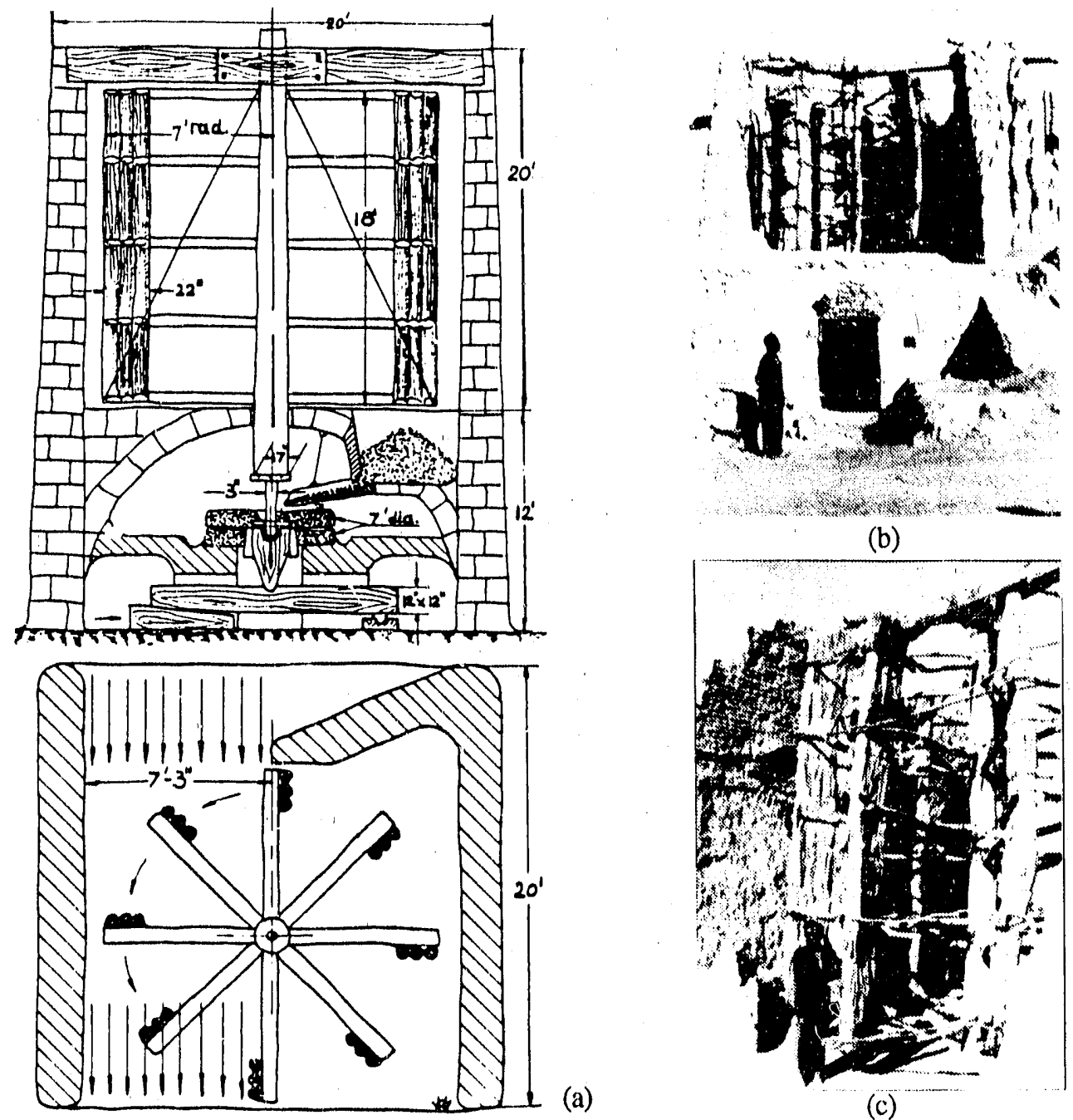

(b)

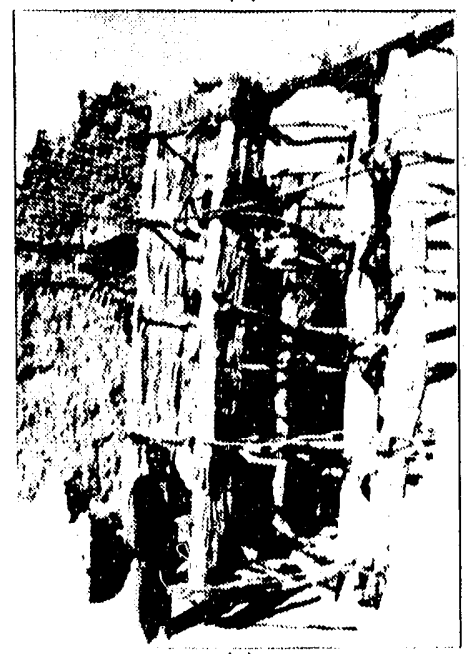

(c)

Figure 1-3. An existing windmill of the Persian type in Neh. (a) The millstones are now below the rotor and the sails are bundles of reeds [Wulff 1966]. (b) A general view of the downwind (south) wall of the mill. (c) Close-up view of the reed sails. (Reprinted by permission of MI'T Press; $₫ 1966$, MIT Press)

about $56 \mathrm{~cm}$ wide and $15 \mathrm{~cm}$ thick. The tie bars are secured to the spokes by pegs and ropes, and there are several sets of stay ropes to tie the whole rotor assembly together. The system is certainly clastic, as we see in Figures 1-3(b) and (c), and it scems as if it might need frequent adjustment so the millstones can operate with the proper clearance. The thrust block with its "tallow-soaked lubrication pad" also does not seem to make a precise bearing.

Now Wulff gives some figures relating to the performance of these mills. When he visited Neh in 1963, 50 mills were still operating. Each milled an average of a ton of grain in 24 hours, so in a 120-day windy season, they were said to produce a total output of $60(0)$ tons. Based on a wind speed of about $30 \mathrm{~m} / \mathrm{s}$, an effective exposure at alli' time of 1.5 olades, and a mill efficiency of $50 \%$, Wulff estimates a power output of about $75 \mathrm{hp}$ per mill. It is difficult to accept this high figure. A power calculation based on aerodynamic drag would yield only about $16 \mathrm{hp}$ in a $30-\mathrm{m} / \mathrm{s}$ wind.

The basic design of these primitive vertical-axis mills has lasted at least 1000 years, although a major change has come about in that the machine has been inverted, placing the 
sails above the millstones, as we see in comparing Figures 1-2 and 1-3. Wulff suggests that the earlier concept may simply have been taken from the ancient Norse or Greek water mill, in which the mill itself had to be placed over the water wheel [1966]. No comment on when the change might have been made seems to be available, but it certainly made operation much more convenient. Elevating the driver to a more open exposure improved the output by exposing the rotor to higher wind speeds. Other noticeable changes are the use of reeds instead of cloth to provide the working surface and the use of a single entry port in place of the four described by al-Dimashqi, although this may have been limited to the region around Neh, where the summer wind is almost constantly from the north.

It would seem, then, that we can take the tenth century as the earliest known date for acceptable documentation of the vertical-axis windmill, and the location as most probably West or Central Asia. Forbes apparently goes as far as to take the birthplace to be Sistan and to place the invention in early Muslim or even pre-Muslim times. If we take the founding of Islam to be in the first part of the seventh century, this is a good deal earlier than most science historians would consider to be proven. Forbes also asserts that, after having been first confined to Penisia and Afghanistan, the invention subsequently spread in the twelfth century throughout Islam and beyond to the Far East. On the other hand, Lynn White states that there is no evidence that mills of this type ever spread to other parts of the Islamic world [1962].

The belief seems to be quite widespread that the Chinese invented the windmill and have been using it for 2000 years. This might well be so, considering that they developed so many enginecring artifacts, but there is little or no evidence that the windmill was one of them. The eminent scholar Joseph Needham, whose monumental work in many volumes, Science and Civilization in China [1965], is the recognized classic text in the field, states that the earliest really important reference dates back to 1219 . There is a report of a visit in that year to Samarkand by a celebrated Chinese statesman and patron of astronomy and engineering, Ychlü Chhu-Tshai, who in a poem wrote that stored wheat was milled by the rushing wind and that the inhabitants used windmills just as the people of the south used water mills. Later Chinese references to the windmill again all point to its transmission from lands adjacent to western China as being the most likely supposition, and that it was carricd there by sailors or merchants from Central and Southwe it Asia. Needham points out further that the references suggest that the introduction of the windmill took place no earlier, because it never before received a specific character or specific wording; it might have been confused with the rotary winnowing fan, however, which is much older.

The first European to report windmills in China was Jan Nieuhoff in 1656. These mills had a distinctive form, with eight junk slat-sails mounted on masts around a vertical axis and disposed so that they could be positioned automatically. Figure 1-4(a) shows the arrangement of the masts (for clarity, only one sail is rigged), supported from the rotor shaft by radial cross-arms. The power take-off is through a right-angle drive composed of gears with pin teeth. Figure 1-4(b) illustrates the action of the sails as the rotor turns. Each sail is mounted asymmetrically on its mast and held against the wind by a rope (positions $G, H, A$, and $B$ ) until it reaches a point in its rotation where it jibes, reversing its orientation and blowing outward $(C$ and $D)$, coming thence into the eye of the wind or luffing, which gives little resistance to shaft rotation $(E$ and $F)$. Thus, it does not require shielding walls like the Sistan models and can utilize wind from any quarter. This type of mill is still used in eastern China.

Tne real mystery, however, lies in the fact that the vertical-axis Persian windmill never came into use in Northwest Europe. At the end of the twelfth century, there was an efflorescence of a completely different type, the horizontal-axis windmill. This development presents a sccond enigma in the technical development of the wind turbine that occurred some thousand years after the enigma left by Heron's device. But this is a story in itself, and it requires a separate presentation. 


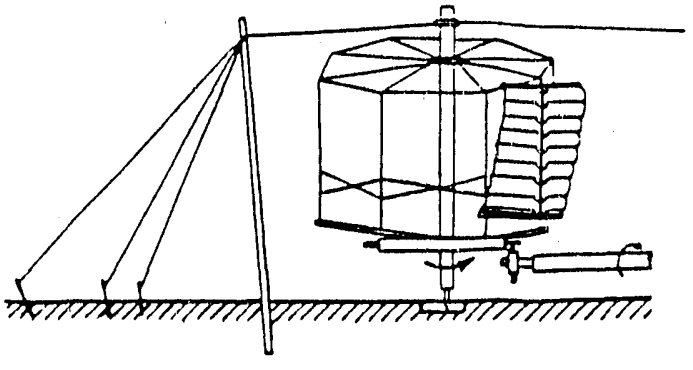

(a)

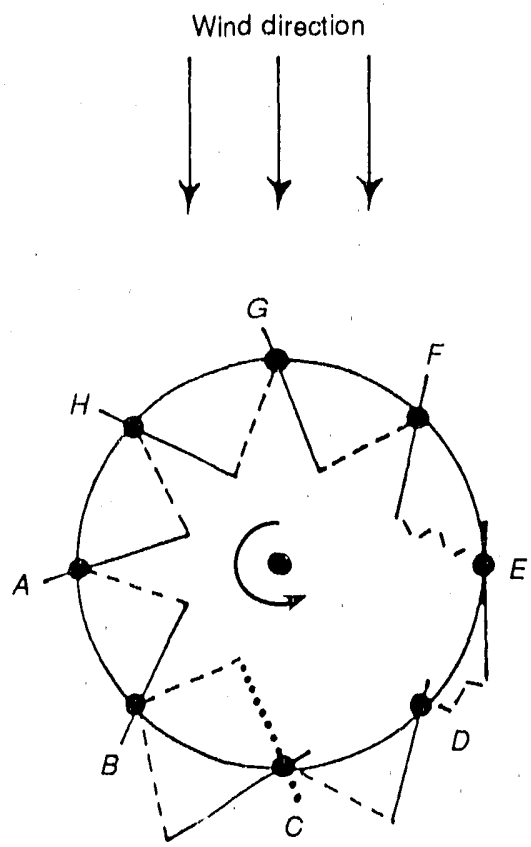

(b)

Figure 1-4. The vertical-axis Chinese windmill, with eight junk slat-sails [Needham 1965]. (a) General arrangement of sails, masts, main shaft, and power take-off. (b) Automatic positioning of sails during rotation. At $E$ and $F$, sails are luffing, presenting little resistance to the wind. (Reprinted by permission of Cambridge University Press; from Chhen Li, Khao Hsung Thung Pao, Vol. 2, No. 3, 1951, p. 260)

\section{The Horizontal-Axis European Windmill}

Northwest Europe, particularly France, Germany, Great Britain, Iberia, and the Low Countries, eventually became the region that developed the most effective type of windmill, one in which the shaft carrying the sails was oriented horizontally rather than vertically as in the Persian mill. In a relatively short time, tens of thousands of what we will call horizontal-axis European windmills were in use for a variety of duties. The familiar cruciform pattern of their sails prevailed for almost 800 years, from the twelfth to the twenticth century.

The Domesday Book registers between 5000 and 6000 mills in England by A.D. 1086, but without distinguishing among kinds of mills, whether hand, animal, water, or wind, so the last of these cannot be assumed to have been in use. For many years, the first windmill in the West was believed to have been located near Bury St. Edmunds in Suffolk, England, because of its unimpeachabie provenance from the famous Chronicle of Joceli 1 of Brakelond, which dealt with the affairs of the abbey, and because of the widespread knowledge of that text from Thomas Carlyle's "Past and Present," which was based on the Chronicle. The story told there is that of Dean Herbert, who in 1191 built a windmill on glebe land. Glebe signifies land attached to an ecclesiastical benefice controlled by the lord of the manor, in this case, the Abbot Samson, who made the Dean tear the mill down. 
Diliprnt and patient scholarship, however, has uncovered the unqualified existence of other milis; f about the same pesiod, c. 1180 to 1100. There are some half-dozen of these: two in France, three in Britain, and one in Syria. There is some disagreement or doubt as to the exact year of some; hence, the hesitancy about the dating. Including the Syrian mill may appear to be irregular in an account of windmill development in Northwest Europe, but the following verse will explain this. White [1962] gives us an eyewitness account (from 1190) of the Third Crusade, which states

\author{
The German soldiers used their skill \\ to build the very first windmill \\ that Syria had ever known.
}

Apart from its early date, this verse is important for another reason, which we will discuss shortly.

The provenances of these windmilis have been the few acceptable ones until quite recently, when light was thrown on many more of this period, including a number carlier than 1180. A new monograph by Edward J. Kealey is a scholarly treatise registering the locations, the first datable appearances, and the names of sponsors, owners, and lessees of more than 50 horizontal-axis windmills up to the year 1200 [1987]. The earliest of these dates back to 1137. Kealey's main interest is to explore the social context of a technological revolution, and most of his information was culled from overlooked financial records of landowiers of the time. He provides what technical details are available, but these are very limited. Kealey considers that the number of windmills operating during the early part of the twelfth century and beyond has probably been grossly underestimated. So it appears that the origin of the horizontal-axis European windmill has been pushed back a whole half-century, w 1137 . From there, it is only another 50 years further back to the Domesday Book and 20 more years back to the Norman conquest of England.

At the end of the following century, windmills were becoming common in Northwest Europe, but little or no penetration is known elsewhere; in the fourteenth century, they were a major source of power. In spite of the vagaries of the wind, the many appropriate sites for the mills allowed much more flexibility of application than did water mills. Numbers in use are not known for these early times; only very approximate figures can be given for later eras. From the figures of Jannis Notebaar we can obtain order-ofmagnitude estimates of possible maximum numbers $2 t$ any time in the eight centuries from their introduction to the heyday of the multiblad $\mathrm{A}$, windmill in the United States: 3,000 in Belgium, 10,000 in England, 650 in Anjou in Frunce, and 9,000 in Holland [1972].

So we have what seems to have been the sudden eruption and very rapid spread of these windmills, which requires some explanation. But there is also an even more important fact to contend with: the complete change from the vertical-axis mill to the horizontalaxis mill. The European windmill's four sails, possibly flat boards in the earliest instances, were mounted on a horizontal shaft, with each sail set at a small angle with respect to the plane of rotation of the whole wheel. This presented several engineering problems. Three major ones were (i) 'ransmission of power from a horizontal rotor shaft to a vertical shaft, on which the grindstones were set; (2) turning the mill into the wind; and (3) stopping the rotor when necessary, because the wind could nor be diverted or blocked.

The first problem was solved by adopting the cog-and-ring gear shown in Figure 1-5, designed long before by Vitruvius for his horizontal-axis water wheel. To solve the second problem, the bold step was taken of rotating the whole system on a central spindle composed of a stout post supported by heavy beams. This is suggested in Figure 1-6, which is the earliest known representation in a book of this type of windmill and appears as part of an illuminated letter in an English ], alter of 1270 [Wailes 1956]. The third problem, stopping the mill, could be partially solved by tuming it out of the wind and applying a frictional braking action at the outer edge of the large gear wheel shown in Figure 1-5. 


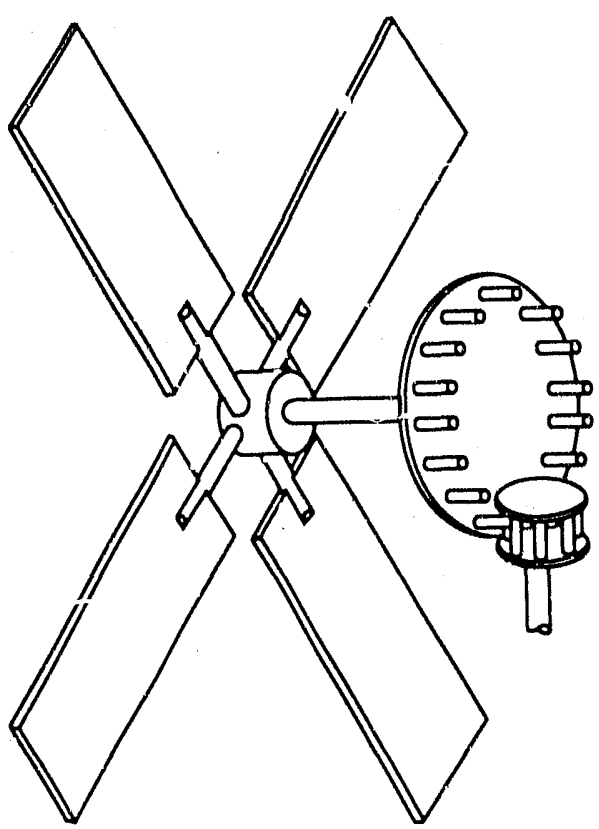

Figure 1-5. Vitruvius' cog-and-ring gear mechanism. This gear made it possible for early horizontal-axis windmills to drive grindstones.

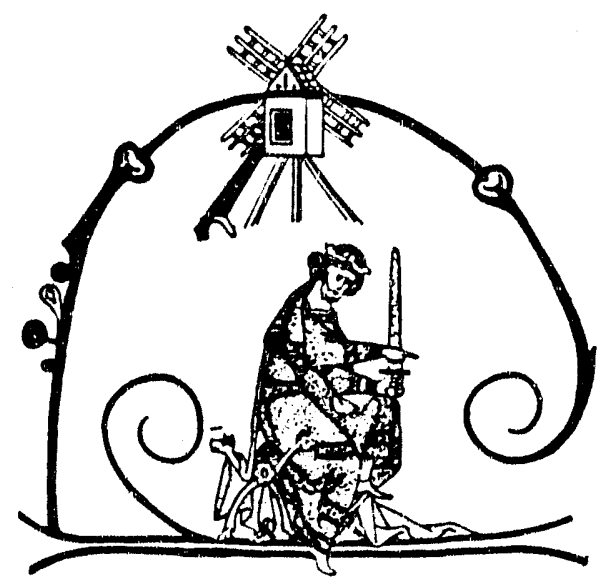

Figure 1-6. The earliest known illustration in a book of a horizontal-axis windmill, from the "Windmill Psalter" of 1270 . The mill is supported on posts and hence is called a post mill [Wailes 1956). (Reprinted by permission of Oxford University Press)
The horizontal-axis windmill was a considerably more complex mechanism than the Persian vertical-axis type, but its adoption is readily explained by the fact that it was so much more efficient. The puzzle lies in the origin of its invention and its sudden appearance in a region that seems to have had no knowledge of vertical-axis windmills. Was it a completely separate inversion, or was it a $c_{4}$ uestion of diffusion of knowledge about wind power from the East, perhaps with a prototype to copy of which no record re ains? Or was it a natural development from the horizontal-axis water wheel? There is no firm consensus, but the opionion among authorities scems to be that this new mill developed naturally from the water wheel. In his discussion of Vowles' paper, "An Inquiry into Origins of the Windmill" [1930], Wailes declares that "he considered the step from the Roman watermill with its horizontal wheeishaft to the ordinary windmill to be easier than from the horizontal windmill with a vertical shaft to the ordinary windmill with a horizontal shaft. All the essentials of a windmill were ready to hand except the sails which replace the blades and rim on the water wheel." Even more flatly, Wailes declares in his book The English Windmill that "the mechanism of the early postmill is like that of an early watermill turned upside-down, the watermill drive being from below upwards and the winamill drive from above downwards; and it is my opinion, in spite of absence of proof, that the origin of the [horizontal-axis] windmill considered from the mechanical standpoint is just that and no more" [1954].

The diffusion theory of origin from the East has some support from those who cannot accept the notion of a single flash of invention. It takes two different forms; one is by virtue of trade routes from East to West, and the other is by virtue of returning Crusaders. Both have credence, but there is no positive evidence for either. Vowles details the spread of the Greek inheritance and the establishment of schools of learning throughout the Near East and eventually the whole Islamic empire [1930]. Many of the centers of learning were distributed alung a great trade route, the old Royal Road, so that a large volume of ideas was spread far and wide, along with the merchandise, from the Baltic to the Far East. He believes that the European windmill was 
first established in Holland, and that because of the omnidirectional wind, as opposed to the Sistan environment, "a new form would therefore be evolved to suit the conditions." Arguments against this notion hold that Holland's first. attested mill came 70 years after those in France and England, and that the Sistan mills were actually far from a major trade route.

The other diffusin , theory holds that between the First Crusade in 1096 and the first known appearance of the horizontal-axis windmill some 50 years later, a large number of people who recognized the potential of the windmill moved to and fro between Northwest Europe and the Middle East and that many of them then pursued the mill's potential in their homelands. This is a feasible theory, but it too lacks positive evidence; the verse quoted earlier about the German soldiers also indicates that the horizontal-axis mill was unknown in the Levant. So it seems that the first solid records we have of European windmills are those from the time of the peevish Abbot Samson of Bury St. Edmunds in 1191 and from the financial records of 1137 to about 1200 that were recently analyzed by Kealey.

Both arguments, however - that for the diffusion theory and that for straightforward aevelopment by upending the driven end of the ordinary water mill - require consideration of another, very innovative step that warrants somewhat more attention than it has received. Although the right-angle gear mechanism allowed the rotor axis to be transposed from vertical to horizontal, the action of the sails also had to be turned through $90^{\circ}$. This was revolutionary, because it meant that the simple, straightforward push of the wind on the face of the sail was replaced by the action of the wind in flowing smoothly around the sail, providing a force normal to the direction of the wind. As a concept, it is indeed a sophisticated one that was not fully developed until the advent of the airplane at the end of the nineteenth century and the engineering science of aerodynamics.

In fact, although they were not aware of it, the first builders of the vertical windmill had discovered aerodynamic lift and had used it to achieve a greatly improved design over that of drag, which is the force that powered the Persian windmills. That the concept of lift is difficult to comprehend, except in precise terms of flow over an airfoil or an edgewise flat plate with an angle of attack, is illustrated by a modern example quoted in a small book of short essays accompanied by ink-wash rendering: of some European windmills by Sir Frank Brangwyn, RA, and Hayter Preston [1923]. In sn introduction, there is a discussion of the comparative power of the horizontal- and vertical-axis types, and another knight of the realm, Sir Daviu Brewster (1781-1868), is quoted thus:

"The planes of these sails of the horizontal-axis windmill are piaced obliquely to the plane of the revolution; so that, when the wind blows in the direction of the axle, it impinges on the surface obliquely, and thus the effort of the sail to recede from the wind causes it to turn upon its axle."

This picturesque, if somewhat anthropomorphic, description is based on drag and not lift, but apparently Brewster's nineteenth-century explanation was acceptable to the twentieth-century authors of the book.

Because understanding the concept of lift and its application to the horizontal-axis windmill does not seem to have been possible in the twelfth century, it is argued that the form came about empirically. However, historians disagree as to the steps that were taken along this empirical path. There seems still to be a logical gap in understanding the transition from the drag to the lift concept; hence, we have no convincing explanation of the sudden ubiquity of the horizontal-axis windmill in Northwest Europe to the exclusion of the vertical-axis type until much later on.

The upshot is that we don't know the answer. Shall we ever do so? The odds might be against it, but Forbes has said (with respect to water mills) that many of the ancient manuscripts have not yet been translated or studied. Likewise, Wailes, in connection with the many earlier references that had proved false before those of c. 1180, states that "there is 
always the hope that some new and fully authenticated ones may be found." One wonders also if all of the manuscripts studied have come under the eye of a scholar who is aware of the importance of references to molinology, and whether heretofore they might have been passed over unremarked. We might remember, too, that it took some 2,00 years for the Dead Sea Scrolls to come w light.

Windmills spread rapidly throughout Europe in the thirteenth century, more or less from west to east, although in view of the relative paucity of authenticated records the appearances we know about are certainly not necessarily the earliest uses. Notebaart provides worldwide coverage, with information on the type of windmill and other details when they are available. It must be emphasized that attested dates of use must have been preceded by a period of development of unknown length, when all designs were guided only by triai and error, and there must have been many early failures (a state of affairs not unknown in the present day).

The pcople of a particular region, which might be as small as a town or as large as a country, are likely to be at least somewhat chauvinistic about their ancient artifacts. This is certainly true of windmills, with respect to who had the earliest, the most, the largest, the best built, the most aesthetically pleasing, and so on. 'The palm would seem to go to Holland for the greatest number per unit of land area and for the widest utilization. The average density of windmills in Holland at their peak was perhaps three times that of England. But then, what country could compete with between 800 and 1000 windmills in a few square miles, as at Zaandam, a suburb of Amsterdam? From the seventeenth century onward, it was a highly industrialized town that used windmills for power as we use electric motors. Or what country had the equal of the 19 large drainage windmills along a mile or so of the Kinderdijk in South Holland?

The windmill is recognized everywhere as a logo of Holland, along with the tulip and the young lady in the traditional costume and white cap. But there the unanimity of opinion ends, and there is much spirited competition to identify the earliest record of the European horizontal-axis windmill and the "best developed" mill. The former is subject to the degree of proof required by the exponent or arbiter. As to the latter, we have no clear winner, and chauvinism could reach its height in attempts to find one.

\section{The Post-Mill Design}

The psalter picture of 1270 (Figure 1-6), referred to earlier as the first known illustration in a book of a European windmill, shows a mill with a long handle to turn it into the wind; the whole body is mounted on a central post supported by offset struts to the ground. This is known as a post mill, and it is the simplest type of horizontal-axis windmill. There are a number of drawings and sketches from the fourteenth and early fifteenth centuries, all showing crude representations, particularly with respect to perspective. Figure 1-7, depicting a mill of 1430 , is given here because it attempts to show a cross section of the interior and the exterior [Usher 1954]. It is very simple and not to scale, but it does show the cog-and-ring gear, the feed of grain to the stones, and the pole for turning the whole structure on the post, which itself is not shown clearly. Note that the pole seems to be drawn as an afterthought, with a peculiar placement; it was normally on the back of the mill for safety and to help in balancing the weight of the sails.

We can only speculate on the development of post mills for some four centuries from their known inception in the middle of the twelfth century, because descriptions and drawings having any significant internal detail have not come to light from that period. It would seem that the first we know of are those of Ramelli in 1588, and excellent drawings they are. It is reasonable to suppose that the first horizontal-axis mills were small, with a fixed orientation, having their foundation members sunk in the ground, because the thrust of the wind on the sails gave rise to large overturning moments that presented a problem. However, the directional variability of the European winds would severely ilimit the energy 


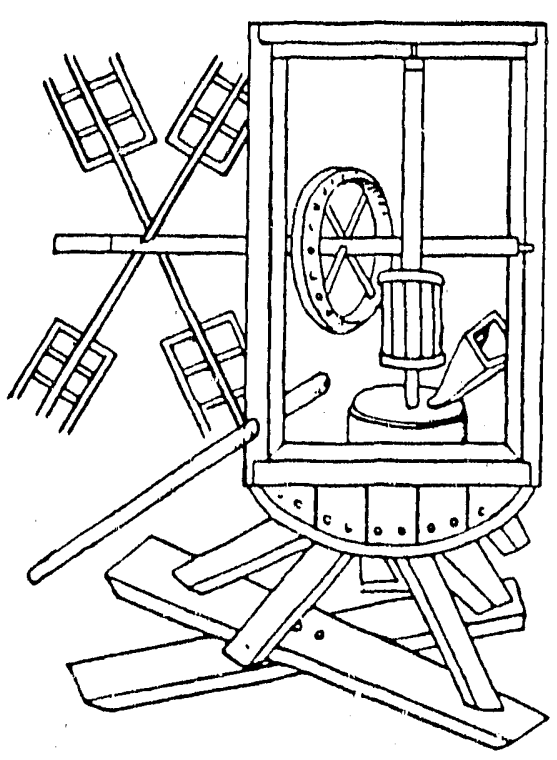

Figure 1.7. A crude sketch of the components of a post mill, c. 1430. The pole at the lower left is presumably for winding the mill [Usher 1954]. (Reprinted by permission of Harvard University Press) output of a fixed-direction mill, so once a sufficiently strong structural design that resisted the large moments had been achieved, a method of turning the mill into the wind must have been sought at an early stage of development. The mounting of the sails, transmission, and grinding stones on a frame that could rotate on a heavy, central post securely fastened to a fixed bottom structure was a bold step; one could expect that many mills were damaged or destroyed by the wind before a suitable design was found.

Before looking at the complete engineering design of a post mill, which is quite complex in its full development, let us look at a diagrammatical sketch of a very common type of post with supporting members, which is the heart of the structural design and gave the mill its name. This is shown in Figure 1-8. The main post, usually a great block of oak perhaps $80 \mathrm{~cm}$ square, is supported by quarterbars nortised in at the top end and anchored to the crosstrees at the bottom with bird's mouth joints. Secured by the iron straps, these joints take the longitudinal outward thrust of the quarterbars. The ends of the crosstrees are supported on masonry piers but are not fastened to them.

Sometimes the bottom of the main post is cut out to provide side tongues fitting loosely over the crosstrees as a steady. It is interesting to note that the best oak for windmills was considered to be from trees about 100 years old!

The top of the main post is shaped to make a stepped bearing or pintle, perhaps $20 \mathrm{~cm}$ in diameter and depth, fitting into the great crowntree, which takes the entire wcight of the rotatable assembly, including the sails, driveshaft, gearing, and millstones, all contained in the housing called the buck. A steady (not shown in the figure) is provided for the crowntrec on the main post just above the quarterbars to prevent excessive swaying in high winds. This was formed by transverse and longitudinal joists, making a frame that fits easily around a circular cross section of the main post at this point. In later models, the wooden steady could be replaced by centering wheels.

In spite of the weight and the absence of antifriction bearings (until later years), the turning maneuver (known as "winding the mill") was apparently carried out without great trouble. The rotation is made slowly and sometimes infrequently, so that the wear in the crowntree bearing is relatively small. As confidence grew in the structural design, the post mill would have developed in size and longer sails would have been used, so that the height of the working floor increased. Eventually, the ladder required to climb into the mill grew to a considerable length, and in the full development of the post mill it could have some three dozen or more steps and weigh half a ton.

Let us turn now from the basic structure of the foundation and the rotatable body to that of the moving parts that the structure carried, namely, the sails, the transmission, and the auxiliaries such as brakes and hoists. These represent a more straightforward design exercise, although each had its problems and probably negligible analytic theory behind it for guidance.

Figure 1-9 is again a simplified diagram of the essentials. The sails, which are not shown in detail because this will come later, are carried on the windshaft, which is supported at its forward or breast end by the large breast beam or weather beam and at its rear 


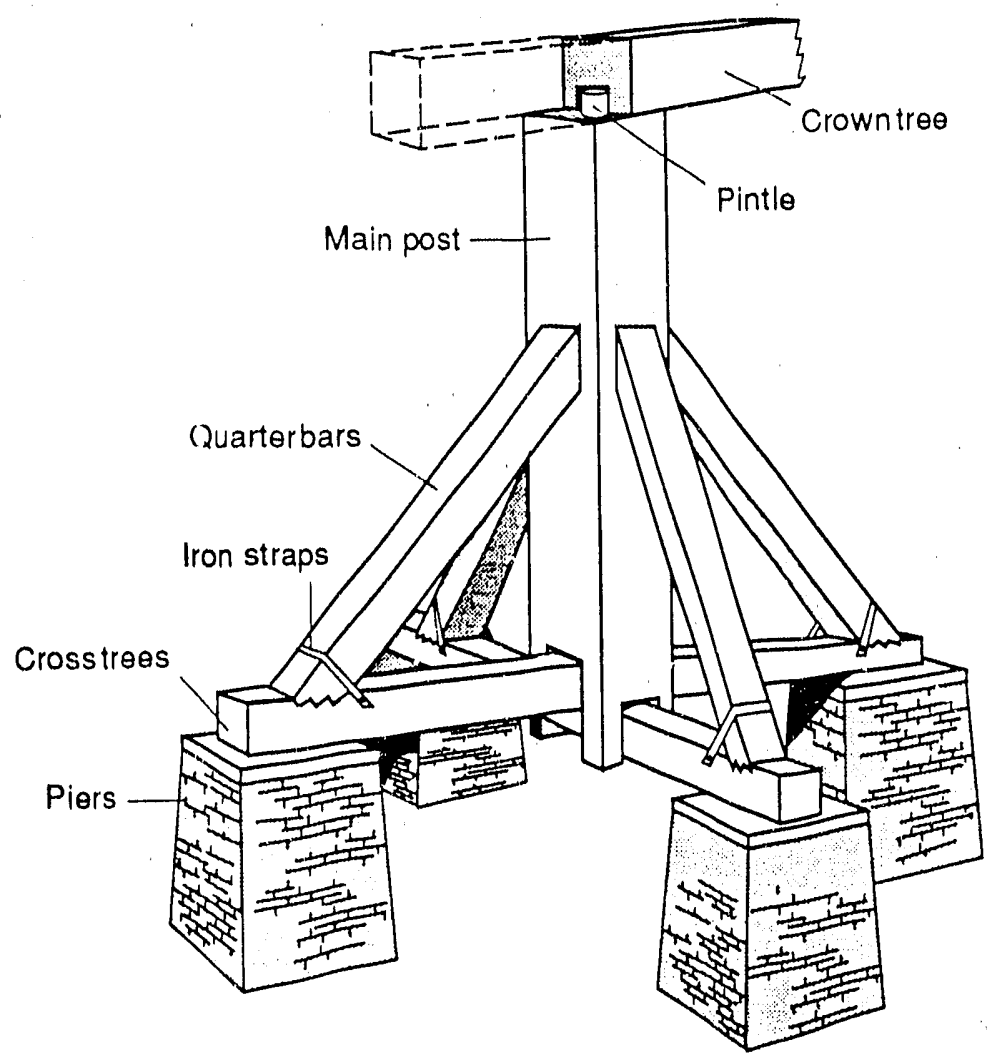

Figure 1-8. Structural components in the base of a post vill. The great main post was usually oak and might be 70 to $80 \mathrm{~cm}$ square.

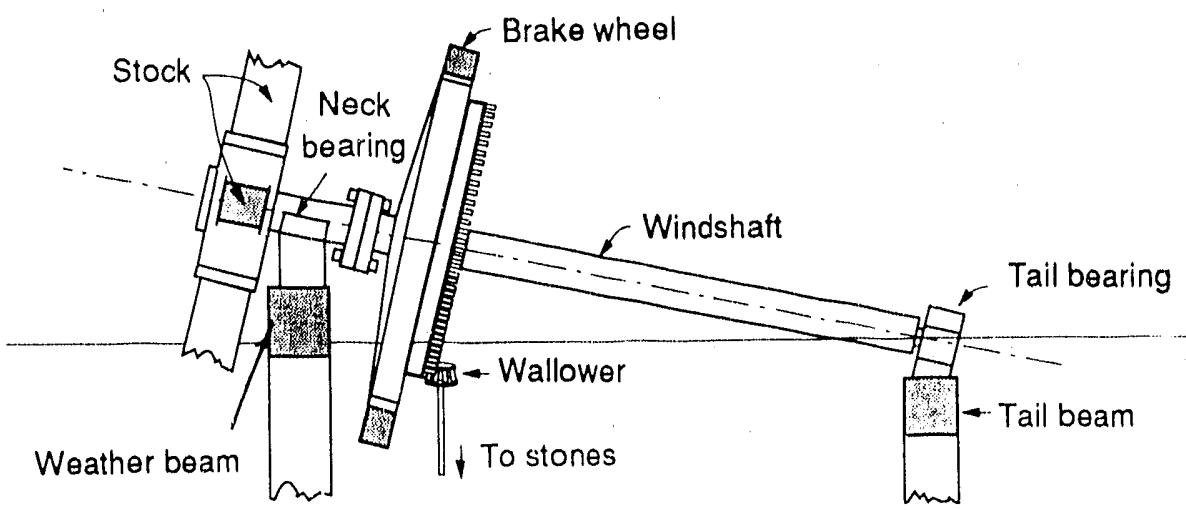

Figure 1-9. The power train of a typical post mill

or tail end by the tail beam. The weather beam supports the neck bearing and thus the weight of the sail assembly, which is considerable. The tail bearing takes the axial thrust which again is considerable, because in this kind of wind turbine, operating on the lift principle, the axial component of force generated by the wind is much greater than the 
tangential component of fore that provides the torque. The weather beam and tail beam transmit their loads by a variety of methods to the buck and the ends of the crowntree, and thence to the main post.

Each pair of opposing sails had a single longitudinal spar or stock, which was mortised through the breast end of the windshaft. In iater years, the stocks were fitted into a cast-iron poll end or canister, thus preventing a weakening of the windshaft by mortising and by exposure to the weather. The neck of the shaft was clad with iron, and the neck bearing was of stone or hardwood, which was later replaced with brass or bronze. Judging by the crude sketches of the first post mills, the windshaft was initially placed horizontally, but quite early on it was inclined some $10^{\circ}$ or so upward from tail to breast. The reasons put forward for this are that it shifted some of the weight of the sail assembly to the tail end and so improved stability, that it allowed longer sails to be used that could still clear the base structure or possibly permit a larger buck, and the sails "could catch more wind." Based on modern experience, inclining the rotor axis presents design difficulties without any improvement in performance, and so it is done only to provide clearance between the blades and the tower. Thus, the second explanation above is the most reasonable one.

The power take-off from the windshaft is made by a large brake wheel, so called because it also carries the brake on its rim. It was fitted originally with hardwood pegs that transmitted the torque to the wallower, or lantern pinion, the vertical shaft of which either directly or via intermediate gears powered the millstones or other devices. As time went on, the wooden pegs or staves became snaped cogs. Iron parts replaced some of the wood, and eventually the brake wheel and wallower developed into iron cross-helical gears. The wooden pegs were lubricated and lasted a surprisingly long time; some are in use to this day.

As illustrated in Figure 1-10, the brake is simply a friction band around the circumference of the brake whecl, made of a number of curved wooden brake blocks banded together, with one end of the band anchored to a timber of the buck, and the other to a brake lever, itself pivoted at a fixed point on the structure. The active end of the brake lever could be pulled up or down by a rope. The brake lever had an iron pin that could engage with a notch in a catch plate, free to swing from a pin in its head. The brake lever was very heavy, and when it was unsupported by the rope or the catch plate, it pulled the brake blocks sufficiently hard against the rim of the brake wheel to hold the wind shaft at rest. Note that the brake wheel has a large diameter, so that a high torque could be produced by the friction on its rim band. The braking device had an element of "fail-safe" in that it had to be lifted to the "off" position.

It was advantagcous to have the brake be capable of operation at a distance, with the miller on the lower working floor. Application of the brake in a high wind or with full sail, either by design or accident, could start a fire from sparks of metal or ignition of wood because of the heavy friction effect. The miller must have had to keep a sharp eye for sudden storms that might catch him with his sails up, so to speak. There was one auxiliary action he could take to control overspeeding, and that was to absorb as much energy in the grinding process as he could - for as long as the supply of grain held out.

The post mill was a triumph of mechanical engineering and the most complex power device of mediacval times, even up to the beginning of the Industrial Revolution, which was initiated by the steam engine of Newcomen at the beginnin of the eighteenth century. A cutaway view of a complete post mill [Freese 1957] is given in Figure 1-11, and Table 1-1 lists its major parts. This is a view of the mill at Brill, Bucks, England, which was built in 1686; it was largely restored by knowledgeable hands, so it is quite representative of the English post mill. The drawing shows many devices and mechanisms, such as those for grinding the grain, dressing the millstone, and hoisting the sacks. The cramped operating quarters will no doubt be noted, and this brings us to the other major type of horizontal-axis European windmill, the tower mill, which was larger than the post mill.

This description gives the basic construction of the post mill, but designs change in detail from mill to mill, region to region, and country to country. This is necessarily true with respect to materials available locally. It is very difficult to date mills, because even 


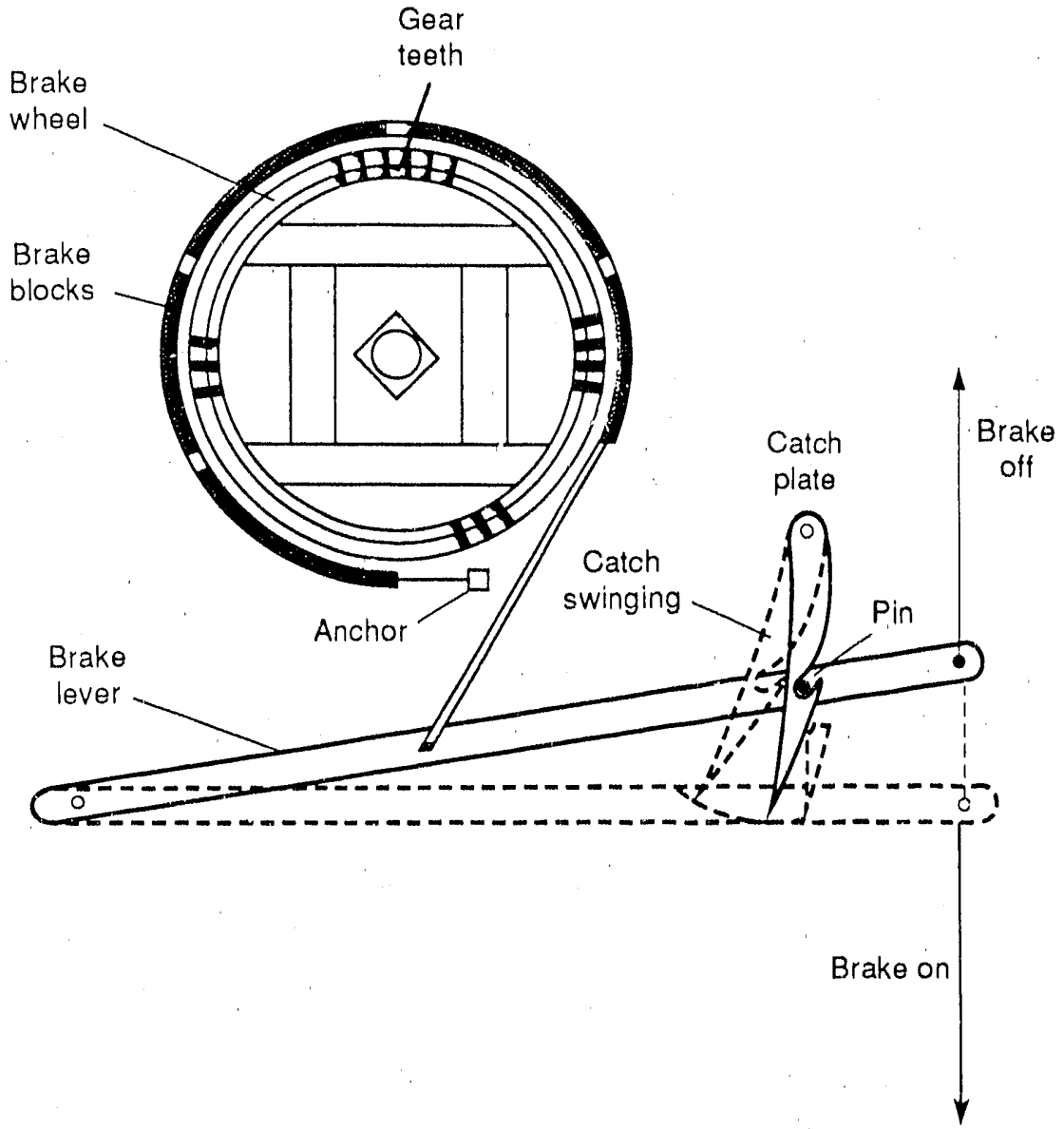

Figure 1-10. Diagram of a post-mill brake

Table 1-1. Parts List of the Brill Post Mill Shown in Figure 1-11 [Freese 1957]

\begin{tabular}{|c|c|c|c|}
\hline 1. Brick piers & 24. & Sail cleat & 47. Hopper \\
\hline 2. Main post & 25. & Brake wheel & 48. Damsel \\
\hline 3. Crosstrees & 26. & Brake & 49. Feed shoe \\
\hline 4. Quanterbars & 27. & Brake chain & 50. Spring stick or "rabbet" \\
\hline 5. Retaining straps & 28. & Brake lever & 51. Feed adjustment cord \\
\hline 6. Heel, or tongue, of main post & 29. & Wallower & 52. Feed adjustment screw \\
\hline 7. Centering wheels & 30. & Upright shaft & 53. Meal spout \\
\hline 8. Crowntree & 31. & Glut box on spindle beam & 54. Bell alarm \\
\hline 9. Side girt & 32. & Bridge beam & 55. Sack-gear "take-off" \\
\hline 10. Diagonal brace & 33. & Great spur wheel & 56. Sack bollard \\
\hline 11. Cap ribs & 34. & Stone nut & 57. Sack control lever \\
\hline 12. Steps or ladder & 35. & Crossbar or bridgepiece & 58. Sack chain \\
\hline 13. Weather beam & 36. & Upper or runnerstone & 59. Sack trap \\
\hline 14. Windshaft & 37. & Rhynd or mace & 60. Dresser case \\
\hline 15. Tail beam and bearing & 38. & Bridgetree & 61. Auxiliary "take-off" \\
\hline 16. Sail stock & 39. & Brayer & 62. Auxiliary gear frame \\
\hline 17. Poll head or canister & 40. & Tentering rod & 63. Dresser gears \\
\hline 18. Sailshaft or whip & 41. & Tentering screw & 64. Dresser \\
\hline 19. Sail bars & 42. & Stcelyard & 65. Wire brushes \\
\hline 20. Uplongs & 43. & Governors & 66. Dresser spout \\
\hline 21. Ilemlath & 44. & Grain bin & 67. Tail pole \\
\hline 22. Windboard & 45. & Grain spout & \\
\hline 23. Curtain rail & 46. & "Horse" & \\
\hline
\end{tabular}




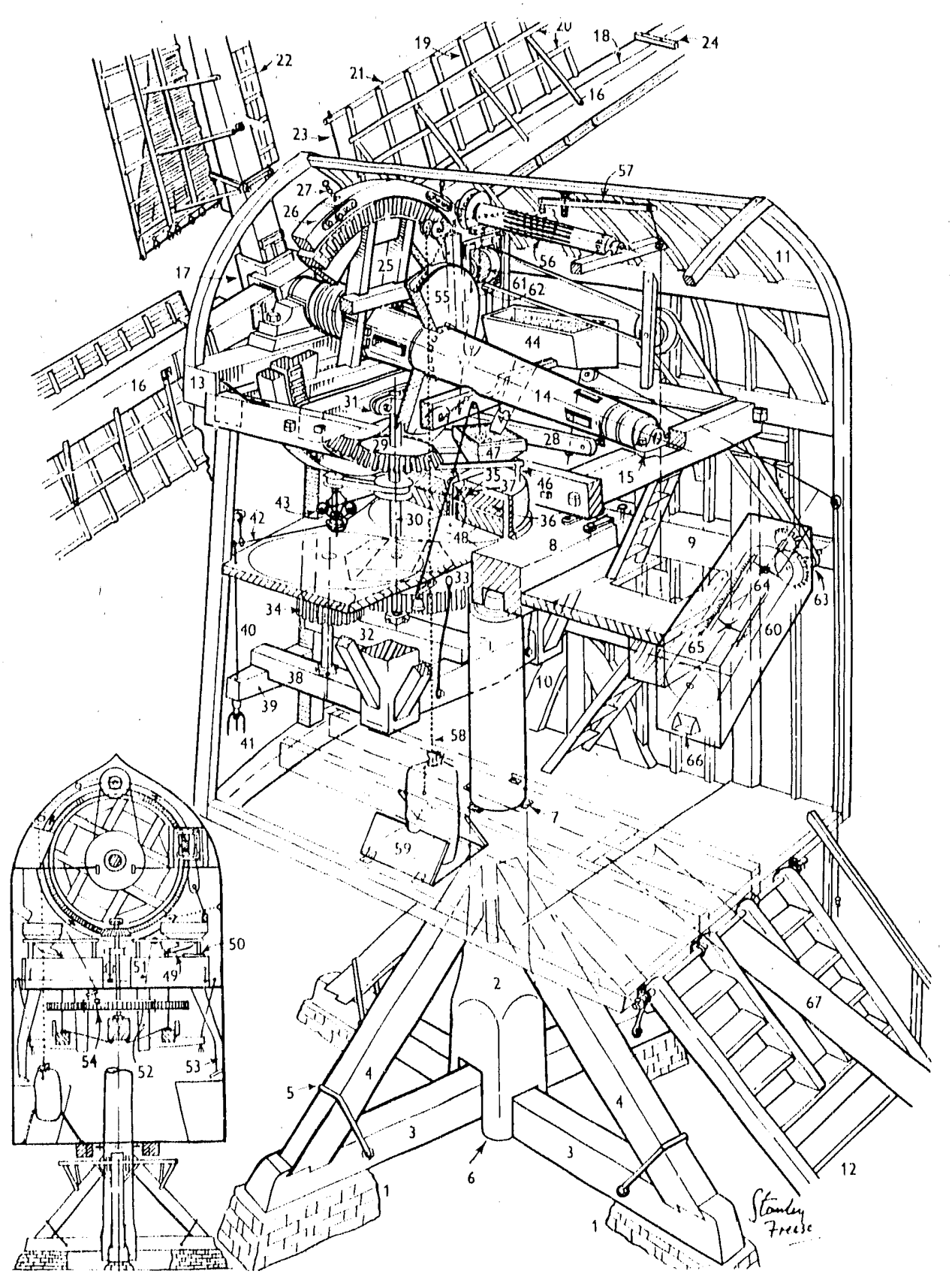

Figure 1-11. Details of the complex construction of a fully developed English post mill at Brill. The names of the parts are listed in Table 1-1 [Freese 1957]. (Reprinted by permission of Cambridge University Press)

when a date is carved into the wood, who knows when it was actually carved? Some documentar' evidence is required before the date can be authenticated. Of course, all the mills had a limited life, even when what we now call retrofits were made. The oldest post mill still standing in the United Kingdom is certified to be from at least 1636, by documentary 
evidence. This is not the date of its building but of its known existence at the time, so the mill may be older yet.

\section{The Tower-Mill Design}

In order to be able to make larger mills, builders had to take another major inventive step: changing the design from one in which the whole body of the mill had to move to face the wind to one in which only the sxils, windshaft, and brake wheel had to move. This was accomplished by mounting the windshaft assembly in the cap of the mill, which turned in a curb or track mounted on the top of a fixed tower. The fact that the mill tower was fixed allowed it to be larger in cross section and higher than the post mill. It could now be made of brick with a circular cross section or of wood in an octagolal shape. The mills made of timber were covered with clapboarding in England and of ten painted white, so that they came to be called smock mills, from their supposed likeness to the rural smock or frock. Many Dutch tower mills had a brick base and a rush-thatched body. There was little difference in the machinery and sails of either type, except for those engaged in specific applications, such as sawmills, which did require some special design considerations.

The tower mill seems to have been introduced in the fourteenth cintury. The earliest representation is given as 1390; a traveler's sketch dated 1420 shows several located in the Byzantine town of Gallipoli. Many such tower mills are still extant in Holland. Some now inside the modern towns were originally on walls bounding the old towns and were more casily defended than post mills. Many observers might agree with Wailes, that "the bestconstructed tower- and smock-mills are to be found in The Netherlands; these cannot be rivalled elsewhere, and the Dutch always led in the design of cloth-spread mills" [1957].

Figure 1-12 shows an elevation section through a large Dutch tower mill [Stokhuyzen 1965]. Its essential difference from the post mill is the cap, which contains only the windshaft and the brake whecl. Its size was kept small, and its external design was varied according to the degree that the effect of its shape on the wind flow behind the sails was recognized, and perhaps according to the aesthetic sense of the millor or the builder.

The top of the tower had to be of stout construction and had to have two essential features. The first was the provision of a fixed curb or rail on which the cap could turn with a minimum of friction between the horizontal surfaces through which the gravity load was transmitted. The second feature was a means of keeping the cap truly centered, again with a minimum of friction between vertical fixed and moving surfaces through which thrust loads were carried. The horizontal bearing was initialiy wood blocks sliding on a curb, well greased, or with iron plates fixed below the cap frame. Later, iron trolley whecls were mounted on the cap ring, and finally, iron roilers were placed between special iron tracks attached to both tower curb and cap ring, so that a roller-bearing was effectively formed.

Figure 1.12 shows the greater room available with twin drives to a pair of stones, an economical way of increasing output without increasing the tooth loads on the great spur whecl or the size of the stones. Many tower mills were built with a staging or deck around the tower at the level of the sail tips, to reduce the amount of effort that had to be expended to climb up and down the steep ladders to make changes in the sails. There was also room for living quarters for the miller and his family, which made the mill quite as commodious as the small, "two-lpp, two-down" cottages of the workers. A tower constructed of bricks could be very sturdy and resistant to weather, but it was not easy to repair if splits appeared as a result of a shift in the foundation or because of the constant vibrations. Thus, the usual practice of placing windows in a linearly symmetrical pattern (as in Figure 1-12) was sometimes changed to a spiral pattern to avoid lines of structural weakness. Wooden smock-mill towers, on the other hand, were subject to joints opening and subsequent rotting from water scepage. Their multisided tesign included walls with slanted corner posts and beams with beveled ends, all of which required expert craftsmanship and constant maintenance to make them secure and leak-resistant. 
Brown states that the largest windmill ever built in Europe was a tower mill $37 \mathrm{~m}$ high to the top of the cap and $12 \mathrm{~m}$ in diameter at the base [1976]. Its rotor diameter would have been at least $30 \mathrm{~m}$, based on the proportions in Figure 1-12. It was built in East Anglia (U.K.) in 1812 and demolished in 1905, after being severely damaged in a storm. What may have been the largest-diameter tower mills ever built were a pair erected in San Francisco's Golden Gate Park to pump water to a hilltop lake [Torrey 1976]. Built in 1902 and 1905, they had rotor diameters of $34.7 \mathrm{~m}$ and towers about $24 \mathrm{~m}$ tall.

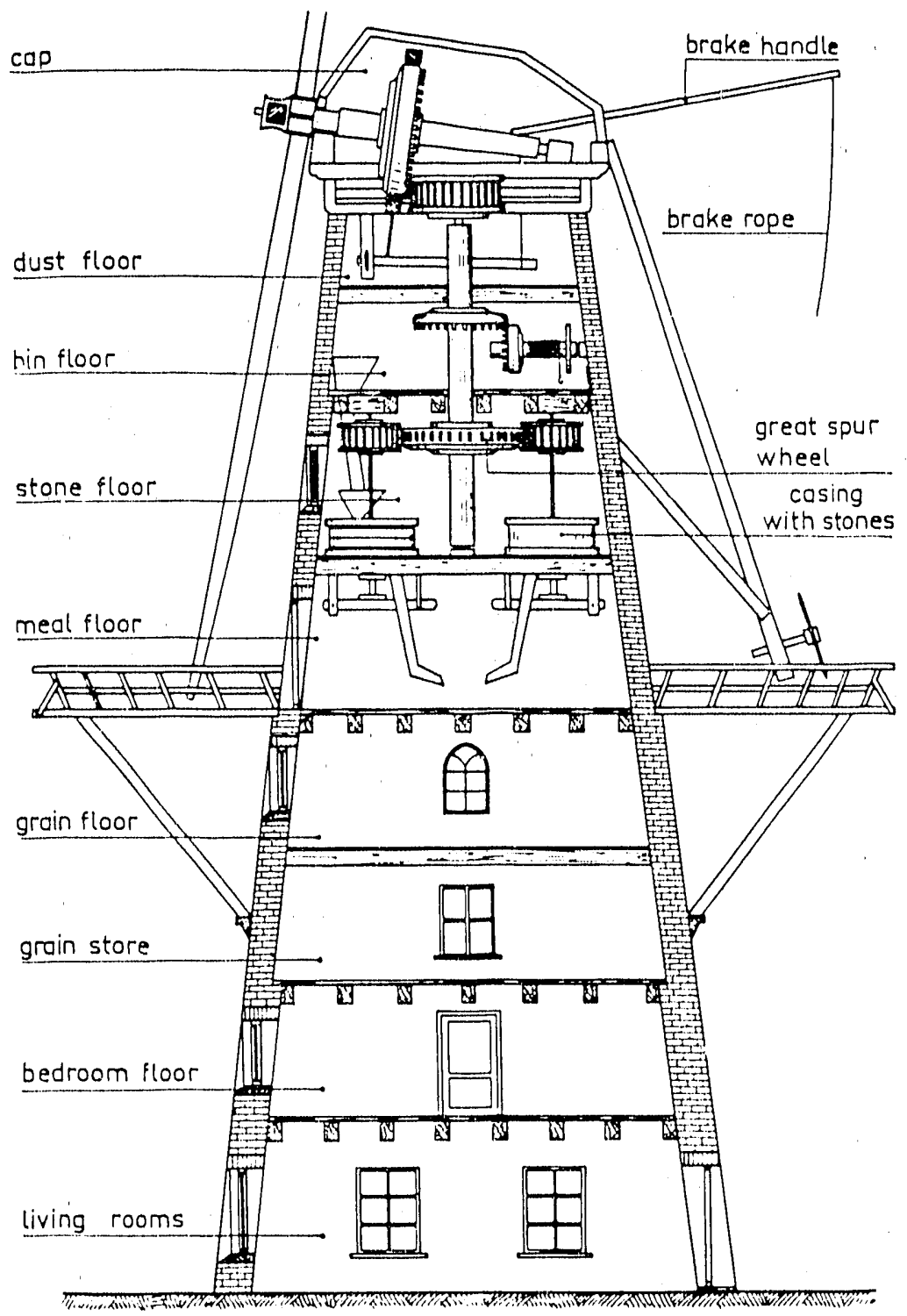

Figure 1-12. Cross-sectional view of a large Dutch tower mill with dual millstones and living quarters [Stokhuyzen 1965] (Courtesy of DeHaan/Unieboek) 


\section{Applications of European Windmills}

Thus far we have taken the European mill to be a grain mill, but it was also used in a host of other ways. One very considerable application was for pumping water; one naturally thinks of The Netherlands in this regard, because the Dutch were always engaged in either keeping out the sea or turning it back when it got in. Although they were not the first to adapt the windmill for drainage, the Dutch quickly developed the wipmolen or hollow post mill, one of the designs developed specifically for pumping water. This "pumping" was done by a scoop wheel, as illustrated in Figure 1-13, with a lift limited to $1.5 \mathrm{~m}$ at the

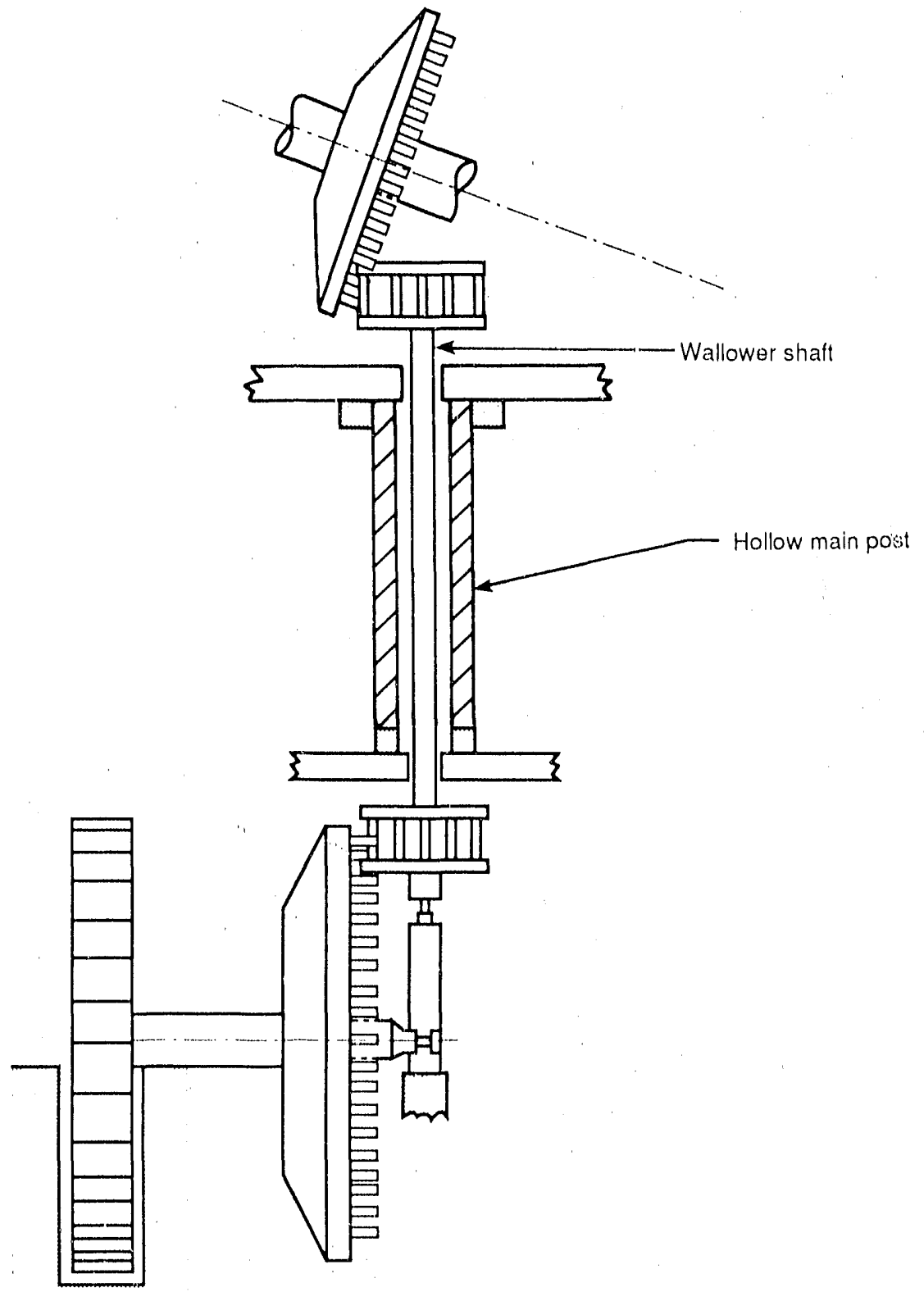

Figure 1-13. Diagram of the power train of a Dutch wipmolen, a post mill adapted for pumping water. The wallower shaft passes through a hollow main post. 
most. The plane of rotation of the scoop whecl had to remain stationary when the mill structure yawed with the wind. To accomplish this, the solid main post of the original post mill was replaced with a hollow one that allowed the vertical shaft from the wallower to extend down the inside of it. At the bottom end, there was a right-angle drive formed by a second cog-and-ring mechanism. In later years, the tower mill was also adapted as a drainage mill; these were often grouped together to drain the Dutch polders and keep them drained. A most striking example of this is the Kinderdijk group mentioned earlier.

Another special windmill application, which again was developed and used widely in The Netherlands from 1600 onwards, was as a sawmill. It, too, was originally an adaptation of the post mill, called a paltrok, in which the brake wheel drove a vertical gear wheel that turned a horizontal crankshaft. The end of a long, vertical connecting rod from the crank was fixed to a saw assembly, which cut the timbers longitudinally into planks by an up-and-down motion. Tower mills were also used later as sawmills, because their greater size and power allowed somewhat larger logs to be sawn or more saws to be used in parallel, leaving the smaller work to the paltroks.

There was a multiplicity of industrial applications of windmills in the seventeenth century and onward, particularly in The Netherlands. The countless waterways fron the sea allowed timber, spices, cocoa, snuff, mustard, dyes, chalk, paint pigments, etc., from all over the world to be processed straight from the cargo ship and transported throughout Europe and beyond. The Zaan district was the industrial center, and windmills were the electric motors of their day. Some odd applications have been suggested over the centuries, and one must admire the ingenuity of two of these, both for military use. One was as the motive power for what might be called an armored chariot (a suggestion which preceded that of the tank by about six centuries), and the other for hurling hives of bees over the walls of fortifications (perhaps a precursor of shrapnel or the anti-personnel bomb).

\section{Windmill Technology Development}

Throughout history, windmill technology represented the highest levels of development in those technical fields we now refer to as mechanical engineering, civil engineering, and acrodynamics. The best technical minds of their day were constantly seeking to improve the design and operation of windmills. A continuous series of modest changes introduced and tested by builders and millers must have occurred that finally resulted in the refinement and advancement of windmill technology. We will now consider some important technical developments in three areas: sails, the heart of the windmill; control devices, particularly those making the miller's work easier and safer; and technical analysis, which determines the factors that influence performance and efficiency.

\section{Development of Windmill Sails}

Windmill sails and their development are topics about which we would like more information, since most of the early designs are known only from a few dated pictures of a general nature. There is no adequate record of sail designs for the earliest years of the horizontal-axis windmill. Through the fifteenth century, we have to rely on crude illustrations and carvings that were quite small and showed little detail. Perhaps sails were at first flat boards, but these were soon replaced by a cloth-covered wooden lattice consisting of transverse and longitudinal battens. This lattice was fixed symmetrically on a central spar, forming two "ladders" through which the sail cloth was laced over and under alternate transverse battens. These early sails were inclined to the plane of rotation at an angle of about $20^{\circ}$ alung their whole length.

There were, of course, some variations. The Mediterranean countries developed triangular lateen or jib-type sails, allied to those of local sailboats, with lighter spars braced to 
each other by guy wires. Although this design is still in use, the date of its first appearance is not known. The sails of the large post mills and tower mills developed chiefly in the countries of Northwest Europe; most of the discussion that follows is concerned with the type called the common sail. Although it was replaced in many instances by improved designs, it was still in use at a very late ciate.

Figure 1-14 shows the structure of the common sail diagrammatically. The main structural element was the stock, which either was mortised right through the windshaft or was fitted into the iron canister or poll end. It could be as long as $27 \mathrm{~m}$; although anything longer might have led to structural problems, it was most likely limited to this length by the availability of the right kind of lumber. Along the length of the stock were fastened narrower timbers called whips, through which transverse sail bars were mortised at intervals. To the sail bars were nailed longitudinal laths, the outside ones called hemlaths and any intermediate ones (one or two) called uplongs. In this way, a lattice was formed on which cloth could be attached. The sail bars were initially placed symmetrically on either side of the whip, but in later times the common sail had the stock positioned as shown in Figure 1-14. We would now call this a fractional chord position with respect to the sail bars, at 1/3- or 1/4-chord, for example. This chordwise location of the stock is discussed in more detail later.

The forward ends of the sail bars supported a leading-edge wind board that directed the wind onto the sail and helped to hold the cloth firmly against the frame. At the poll end there was a transverse iron bar onto which the end of the sail was attached by rings and eye-

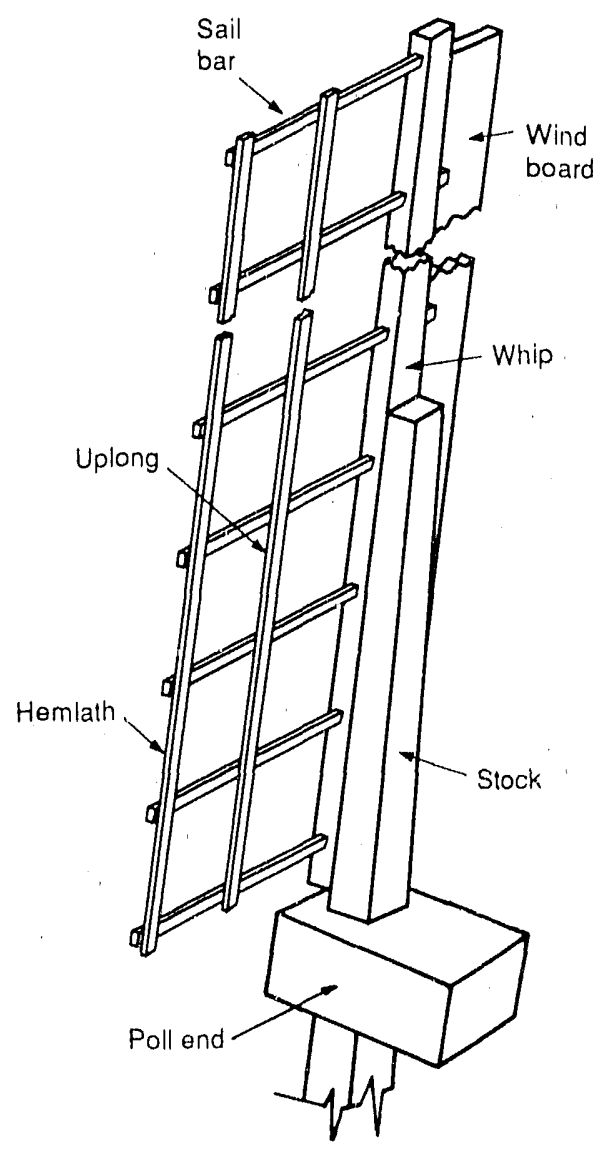

Figure 1-14. Structural components of the common sail lets in the fashion of a present-day curtain. Ropes were attached along both lengthwise edges of the sail so that it could be drawn radially outwards and fastened at the tip. Note that the tip had to be within reach of the miller, standing on or near the ground, or on the tower stage, for those mills that had one.

Furling of the common sail acted to control power and rotor speed much as the variable pitch control does for the modern wind turbine. Pointing lines, additional cords near the tip, allowed the outer part of the sail to be furled back to the whip. When the mill was not operating, the sail was unfastened at the tip, twisted into a roll, and cleated to the whip. This was a considerable improvement over the earlier sail design, in which the spar was at mid-chord and separate cloths on each side of it wound over and under alternate sai' bars, making furling a very awkward task. However, the design of the common sail still required that the mill be brought to rest when the sail area had to be rearranged, so the miller had to be able to draw the brake very tightly to ensure that the sails did not sweep him away in a gust of wind.

The earliest sails were inclined at a constant angle to the plane of rotation, whereas the common sail was given a twist from root to tip to vary the inclination continuously along its length. This was called weathering the sail, and it was done by mortising the sail bars through the whip at different angles 
which, according to Wailes, might vary from $22.5^{\circ}$ at the root to less than zero at the tip [1954]. This was undoubtedly an empirical discovery, because it is unlikely that the millwrights were aware of the concepts of relative velocity and angle of attack. Perhaps weathering was prompted by observations of the behavior of the stretched cloth along its length "catching the wind" or "filling the sail." What seerns somewhat surprising is that it was carried out as far as placing tip sail bars at a negative angle. Although negative blade pitch is now recognized as being theoretically correct in some instances, in those days it must have looked wrong when the mill was at rest.

Jan Drees put forth some observations on the design and performance of windmill sails based on his studies of sixteenth- and seventeeth-century paintings, etchings, and engravings of rotors, comparing these with the features of modern rotary wings, i.e., of helicopters and the like [1977]. As a rotary-wing engineer, he was amazed to find that such modem design features as nonlinear blade twist, leading-edge camber ("droop snoot"), and fractional-chord position of the main spar (stock) could all be found on the sails of largediameter windmills of the seventeenth century. Although many of the examples he quotes have been recognized for some time, Drees' contribution is to emphasize a pattem of continuous historical development of windmill sail technology in relation to modern concepts.

Drees developed a diagram of what he considers took place in windmill sail design between the thirteenth certury and today, and this is shown in Figure 1-15. Some of his statements are conjectural, and he acknowledges that a great deal more research is necessary to establish the validity of his contentions. According to Drees, a 1550 engraving by Pieter Breughel the Elder shows for the first time a windmill sail with the stock moved forward from the 1/2-chord to the 1/3-chord position. This approaches the optimum position of $1 / 4$-chord for the aerodynamic center and the center of gravity of modern airfoils, which minimizes twisting moments. This eventually allowed a threefold increase of sail and a corresponding tenfold increase in power over about 100 years. There is still no leadingedge camber or twist shown in the Breughel engraving. Drees considers the 1550 date very close to that of the initiation of the revised stock position, because pictures by Stradanus and Ramelli from the latter half of the sixteenth century and a patent granted to Comelius Muys in 1589 (perhaps the first patent of a windmill) still show the 1/2-chord stock position. Another example of a windmill sail with the stock near the 1/4-chord position is given in a 1589 sketch by Simon Stevin, in his specifications for a drainage mill in Kralinger [Forbes 1966].

By 1650 several pictures by Dutch artists show the stock moved forward, including one by Ruisdael in which the stock is at the 1/4-chord position. There is also one by J. van de Velde in 1617 that shows nonlinear twist, apparently for the first time. In 1664 Jan van Gryen showed a stock all the way forward. Not long after these examples appeared, the wind board shown in Figure 1-13 (corresponding to modem leading-edge camber) was introduced, utilizing the $25 \%$ of chord between the leading edge and the whip

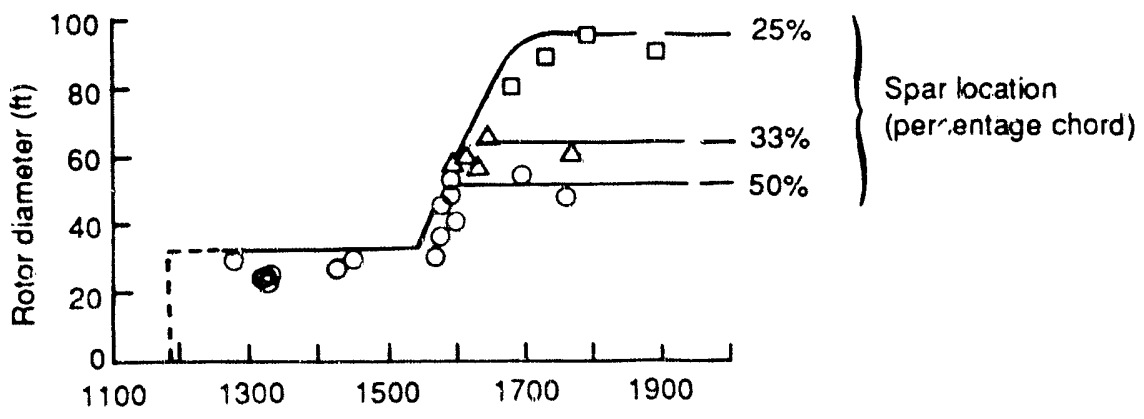

Figure 1-15. Historical development of windmill sail geometry, showing trends in size and the location of the spar or stock [Drees 1977] 
to direct the wind efficiently around the sail itself. Thus, windmill sails were provided with four characteristics of today's rotary-wing blades: leading-edge camber, 1/4-chord spar position, 1/4-chord center of gravity, and nonlinear twist.

\section{Windmill Control Devices}

We see, then, that from sometime in the latter half of the twellth century, the sail developed from a flat board to an efficient cloth sail with twist, a cambered wind board, and a near-optimum stock position. It took some 500 years to accomplish this, and it was not until another century had elapsed that any other major design improvements appeared. When they did so, they were mostly in the form of operational innovations to ease the heavy work of the miller and to make that work more effective by automating some of the necessary but time-consuming and unproductive procedures. Three of the major improvements were made to (1) mechanically change the sail setting, (2) improve braking, and (3) automatically wind the mill. These were all specific inventions with known sponsors, although several variations in design appeared some time later. Most of these improvements took place concurrently with the Industrial Revolution, a timu rich in mechanical invention.

The first device we consider, for the setting of the sail, was the spring sail invented by Andrev' Meikle in 1772, in which a number of hinged wooden shutters mounted transversely across the stock replaced the sail cloth. These shutters Gerated like venetian blinds tied together by a longitudinal bar and iron cranks that opened and closed them simultaneously. At full power, the shutters were closed and presented a flat surfare to the wind. Excessive wind speeds caused the shutters to open and spill the wind. The movement was controlled by a spring; the initial setting was made with the mill at rest, and once it was adjusted, the speed of the mill could be kept reasonably constant. Spring sails were somewhat less efficient than the common sail because the shutters could not be weathered satisfactorily. Thus, sometimes a mill would have two common sails and two spring sails, as a compromise between output and steady running.

The second device was that of Stephen Hooper, who by 1789 had replaced each of the stiff slats in the spring sail with a flexible roller-reefing sail. His main contribution to the state of the art was a rotor control device in which furling was activated by a long striking rod that passed right through a hole bored centrally down the entire length of the windshaft. A cross or spider was affixed to the poll end of the striker. Each of the four "legs" of the spider was connected by a lever to a bell crank, which operated a longitudinal rod along the stock of a sail. In turn, this rod operated bell cranks fixed to each roller or shutter. In this manner, a linear motion of the striking rod caused simultaneous opening or closing of all the individual segments of the sail.

As Wailes notes, the hole for the striking rod was drilled from the tail end of the windshaft to the poll with the mill turning, the stationary drill being lengthened $0.5 \mathrm{~m}$ at a time. This must have required excellent craftsmanship as well as courage on the part of the millwrights. There were no laser-guided drills in those days!

At the tail end of the windshaft was a rack-and-pinion mechanism attached to the striking rod together with an endless chain that reached to the ground or a convenient lower level. Pulling the chain turned the pinion, thus moving the rack and hence the striking rod. Apparently, the roller-reefing sail was not successful, but the spider control mechanism was retained by William Cubitt, who amalgamated it with the shutters of the spring sail to form his 1804 patent sail. A further improvement was to attach weights to the endless chain to keep the sail shut until the wind speed increased and exerted sufficient pressure to open the shutters. Thus, the patent sail effected automatic sail setting and relieved the millers of much arduous labor.

In France, Berton introduced a different orientation of the shutter around 1840 . Instead of being in the transverse position, the shutters were fitted longitudinally for the 
whole length of the stock and were pivoted so that they could close to make an almost flat surface. When open, they were positioned one behind the other, as seen from the leading edge of the sail. They had to be operated manually from inside the mill and we : used extensively in France.

In addition to their use as sail elements, shutters were also utilized as aerodynamic brakes. There were several varieties, with one, two, or three shutters fitted longitudinally at the outer end of the sail in remarkably similar fashion to the aileron control surfaces of some modem experimental wind turbine blades. In his 1860 design, Catchpole used tw: 0 such shutters placed at the leading edge of the out'ward third of the patent sails. These longitudinal shutters were operated by the same mechanism as the transverse shutters. When closed, they provided additional sail area. When opened, they were at an angle to the plane of rotation of the sail assembly and hence, being outboard, could rapidly produce a strong braking action. They were called Catchpole's skyscrapers. Another aerodynamic brake design consisted of two or three shutters again arranged longitudinally near the tip but located on the trailing side of the whip in place of some four or five transverse shutters.

The third major advance was the invention of the fantail, a device that automatically carried out the operation of winding or yawing the mill. Before this time, post mills and the caps of tower mills were turned manually to follow the wind. As the size of windmills increased, the effort to lift up the tail pole and turn the structure became considerable, so a winch was added to do the job. The invention of the fantail in 1745 by Edmund Lee allowed the wind itself to do the work. The device consisted of a small windmill with some half dozen vanes turning on a horizontal axis set parallel to the plane of rotation of the main sail assembly. With the wind blowing squarely on the latter, the fantail was edge on and developed no work. When the wind direction changed and blew at an angle to the main sails, it did the same to the fantail, which then developed power. Through gearing, the small fantail turned the mill bodily until the sails were again athwart the wind and the fantail action stopped. On the post mill, the fan was mounted on a frame fixed to the ladder near the ground, but on the tower mill it was up high on the cap, with a short ladder for access from the cap.

Thus, by the middle of the nineteenth century, these three devices - patent sails, aerodynamic brakes, and fantail - led to a substantial increase in productivity, as we would now say. Note too that the risk of fire and accident was correspondingly reduced, because the sail shutters and brakes permitted faster shutdown and greatly lessened the danger of fire from the frir tion brake.

It seems remarkable that these inventions did not spread from England to the rest of Europe for many decades, and even then they were very sparsely adopted. This seems particularly true for The Netherlands, which had led so much develofment in the previous centuries. The Dutch people have a high repulation in the world of commerce and industry; their resistance to these control devices might possibly have been basied on a judgment that they were not cost-effective. On the other hand, the Dutch have also produced much great art and architecture, and they continue to do so. So perhaps their aesthetic sense was affronted by the replacement of the cloth sail by the wooden shutter and the addition of an odd-looking contraption perched on the cap, which would have spoiled the clean, sparse lines of so many of the Dutch tower mills. Although the main emphasis in Stokhuyzen's excellent small volume on the Dutch windmill [1965] is on history and technology, there is more than a hint of the aesthetic quality of such mills.

\section{Technical Analysis of Windmills: Stevin, Leeghwater, and Smeaton}

Up to this point, this story of the windmill has been one of relating the development from records that consist largely of pictures, drawings, desc 'ptionis, and, from later years, remaining structures in whole or in part. That is to say, this has been an account based on empiricism in design and on practice in working. Beginning at the end of the sixteenth 
century, however, Simon Stevin and Jan Adriaanzoon Leeghwater* made some attempts to analyze the performance and construction of windmills. These were largely given to the calculation of loads on the internal components and to the hydraulics of the pumping process, particularly of the scoop wheel, so important for drainage uses. Around the middle of the eighteenth century (that is, 150 years later), John Smeaton made a major contribution in formulating the rules governing the output of a mill. This he did by ingenious experimentation with rotor models; he then reduced his test data to simple mathematical expressions.

Stevin (1548-1620), born in Bruges, was well-known indeed for a range of writings on mathematics, mechanics, hydraulics, military devices, and so on, including music and precepts for citizens! Along with his writings, he had many inventions patented and devised many improved components for a variety of engineering artifacts. In his work on windmills, he concentrated on calculating the relationships between dimensions, speeds, and number of gear teeth in order to estimate output. Mechanics was not a very exact science in his day. The concepts of energy, power, and efficiency were unformulated, and there were often no names for them. However, he was the leader in applying what was available in mechanics and mathematics to practical attempts to calculate the output of a mill in terms of the water raised by a scoop-wheel and to use such calculations to prove his suggested improvements. In a published collection of his notes, "Van De Molens" [see Forbes 1966, p. 327], he gives calculations for some 20 mills, either existing, improved, or projected.

Leeghwater (1575-1650), born in North Holland, lived a generation after Stevin. In his early life, he was a carpenter and millwright who har a natural talent as an inventor and engineer on a large scale. He used windmills in larg? numbers for his drainage schemes and made many improvements over the years. None of these resulted in patents, but his skills were widely recognized at home and abroad. He made his reputation by draining a large lake called the Beemster (which had an average depth of $3 \mathrm{~m}$ ) in one year by using 26 windmills. In another scheme to reclaim a polder (swamp), he used 51 drainage mills pumping out water at the rate of $1000 \mathrm{~m}^{3} / \mathrm{min}$, which works out to an average power output of about $7 \mathrm{hp}$ per mill. His vision was such as to encompass the draining of the Haarlemmermeer with the aid of 160 mills. His study of this was published in 1641 and passed through 17 reprints; the last edition was published in 1838. In 1848, the drainage was finally accomplished after plans were revised several times, but the power was supplicd by steam engines.

Smeaton (1724-1792), who was born in the north of England, came much later than the other two engineers, but he contributed the first sound, basic rules of windmill performance. He was a remarkable civil engineer in several branches of the field, primarily in structures such as bridges, lighthouses (the Eddystone among them), windmills, and water wheels, but also in land drainage, canals, harbors, steam engines, and materials (such as cement and cast iron). Smeaton was above all a very careful experimenter; he taught himself and, by example, many others the application of syster atic experiment to technological improvement.

Smeaton's chief contribution to molinology was his paper entitled "On the Construction and Effects of Windmill Sails," which was given to the Royal Society [1759; see also Tredgold 1836]. The paper makes very interesting reading, and although it was given some 230 years ago, it is still available in many technical libraries. This paper describes what

*His name is handled in different ways. Some authors simply use Leeghwater; others, Jan Adriaanzoon. L. E. Harris tells us that Leeghwater was an adopted addition in later life [1957], and Drees states that the name Leeghwater was given to Adriaanzoon because he emptied 27 lakes with windmills in his lifetime, and that the name literally means "empty water" [1977, 1984]. 
might have been the first use of scale models for obtaining the algebraic relationships governing full-size machines. Smeaton had no wind tunnel to use and so he invoked the principle of Galilean invariance and mounted his model on a whirling arm in still air, as shown in Figure 1-16. He still had few accepted laws of energy or standard units with which to obtain numerical values of power, but at least he could run tests at constant speeds and measure, by the raising of weights, the work done by the rotor.

Figure 1-16 follows the original drawing of Smeaton's apparatus. The rotation of the rotor support arm $(F G)$ was accomplished by the mysterious hand $(Z)$ at the left pulling the cord that turned the barrel on the shaft $(D E)$. Speed was adjusted so that the support arm made one turn in the time the pendulum (VX) made two vibrations. This whirling-arm apparatus was not a new idea, but in his customary manner Smeaton improved on others' work in its construction and then performed a series of considered, methodical tests that would not otherwise have been possible.

Smeaton's model rotor had a sail-tip radius of $53 \mathrm{~cm}$, a sail length of $46 \mathrm{~cm}$, and a sail breadth of $14 \mathrm{~cm}$. The maximum "wind" speed developed appears to be about $2.7 \mathrm{~m} / \mathrm{s}$; hence, the Reynolds number for these tests was very low, about 25,000. This may have affected his conclusions quantitatively if not qualitatively. His results can be summarized as follows:

(a) For flat, untwisted sails, the optimum angle to the plane of rotation should be $15^{\circ}$ $1018^{\circ}$.

(b) Weathered (iwisted) sails should have a twist that gives a concave surface to the wind, and a total twist of $15^{\circ}$ with a tip angle of $7.5^{\circ}$.

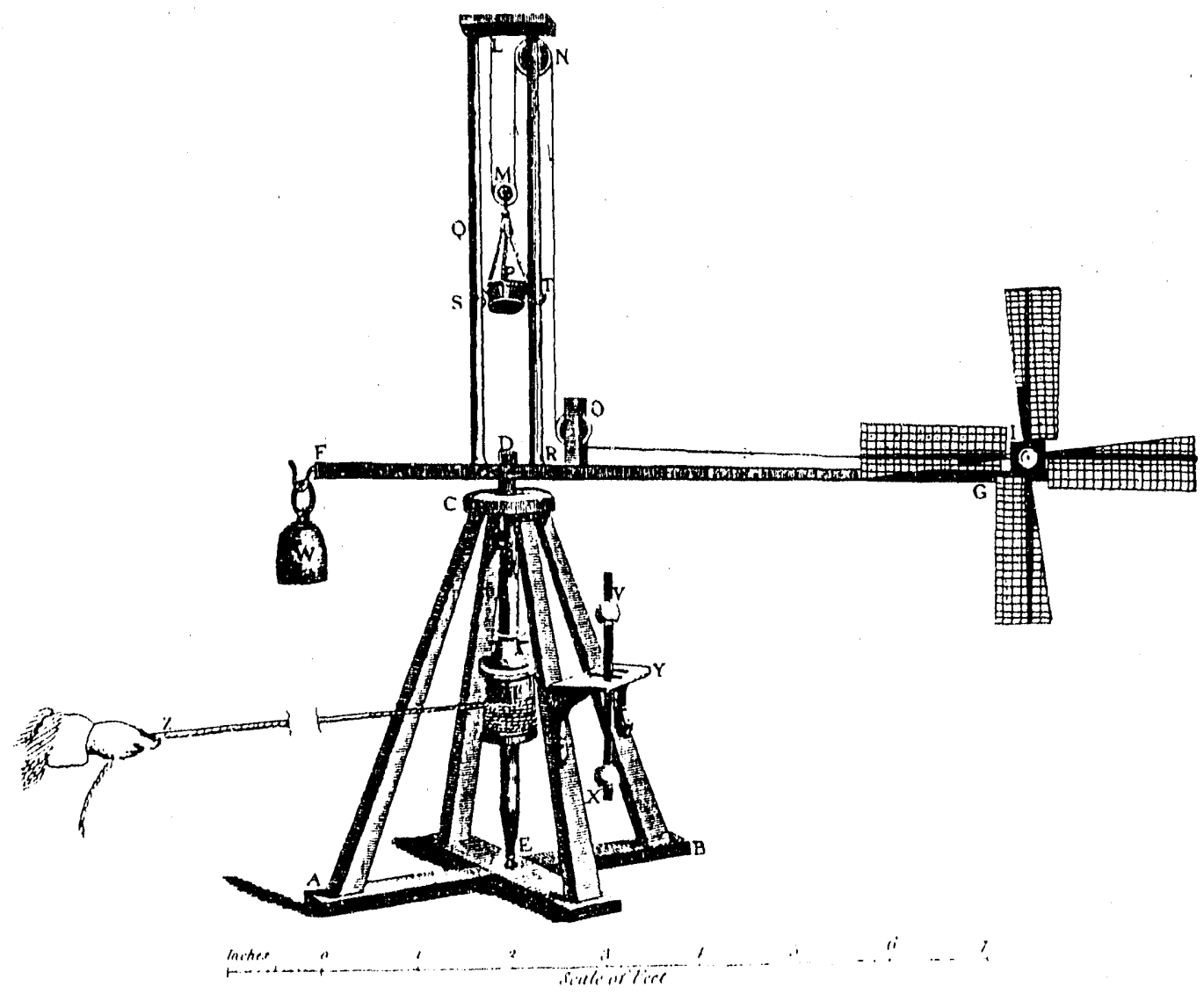

Figure 1-16. Smeaton's laboratory apparatus for testing the performance of model windmill rotors [Smeaton 1759] 
(c) A 25\% increase in the sail area toward the tip (i.e., negative linear taper) together with an increase in blade pitch of $2.5^{\circ}$ yields $28 \%$ more power, achieving optimum power per sail.

(d) Increasing the sail area beyond a certain point decreases the output.

(e) The maximum load that can be lifted is nearly proportional to the square of the wind speed.

(f) The tip speed of the sails in lifting the maximum load is nearly equal to the wind speed (i.e., the optimum tip-speed ratio is unity). Therefore, the rate of lifting the maximum load is nearly proportional to the wind speed.

(g) Hence, as a consequence of (e) and ( $f$ ), the maximum power of the sails is nearly proportional to the cube of the wind speed.

Smeaton's work, however imprecise in measurement, gives basic insights into the process of wind energy conversion, and much of it is still valid today.

In spite of all Smeaton's good work in analyzing performance, the builders who continued with their established designs and practices seem to have taken little notice of it. Of course, some of the labor-saving improvements we discussed earlier were made, but otherwise, there were only minor changes. The steam engine put a brake on the use of wind power, although the established design of the windmill did hang on for a long time, continuing to be built in the early twentieth century. However, in the second half of the nineteenth century a new form emerged, the multivane or annular windmill, which was usually small but capable of satisfying the needs of a farm or ranch with respect to pumping water. In the United States, every farm had one or more of these multivane mills, and the type has come to be called the American windmill. This is a useful characterization in the same sense as the term $D$ :tch windmill, and thus it is so designated here.

\section{The American Windmill}

For this history of the American windmill, we lean heavily on A Field Guide to American Windmills by T. Lindsay Baker [1985]. This is not a pocket handbook like the well-known field guides on birds, flowers, and so on, but a remarkable, large-page book of more than 500 pages. It is certainly the most comprehensive catalog of American windmills and their makers, culled largely from manufacturers' literature and from periodicals of the farm implement industry, in considerable dttail where available. The "field guide" part is preceded by some 100 pages of history, development, and general information about the industry and its technology. It is concerned only with the period from the introduction of a prototype unit by Halladay in 1854 to the essential end of production of these machines in the 1930s.

Figure 1-17, from Baker, shows many of the different designs of the American windmill. Dozens of manufacturers erected windmills at the World's Columbian Exposition in Chicago in 1893, with every conceivable configuration competing for recognition and scrambling to get a piece of the market; an excellent photograph of this event is reproduced in Torrey [1976].

First, let us give consideration to the origin of the design and function of the American windmill. Daniel Halladay is credited with the invention of the first commercially successful, self-governing windmill in 1854; although there were some previous ventures, the Halladay Standard came to be the archetypal American model. It was intended as a small unit ( 2 to $5 \mathrm{~m}$ in diameter) for pumping, as were most other American mills. The output of a mill $5 \mathrm{~m}$ in diameter in a $7-\mathrm{m} / \mathrm{s}$ wind was about a horsepower or so, quite adequate for a "water pumper" on farms all over the country. In later years, some much larger oncs (up to about $18 \mathrm{~m}$ in diameter) were built for industrial and railroad water-supply systems.

The Halladay mill initially had four rotatable, flat, wooden blades joined to an iron shaft with a crank at its opposite end. A solid wooden tail vane attached to the shaft and set 


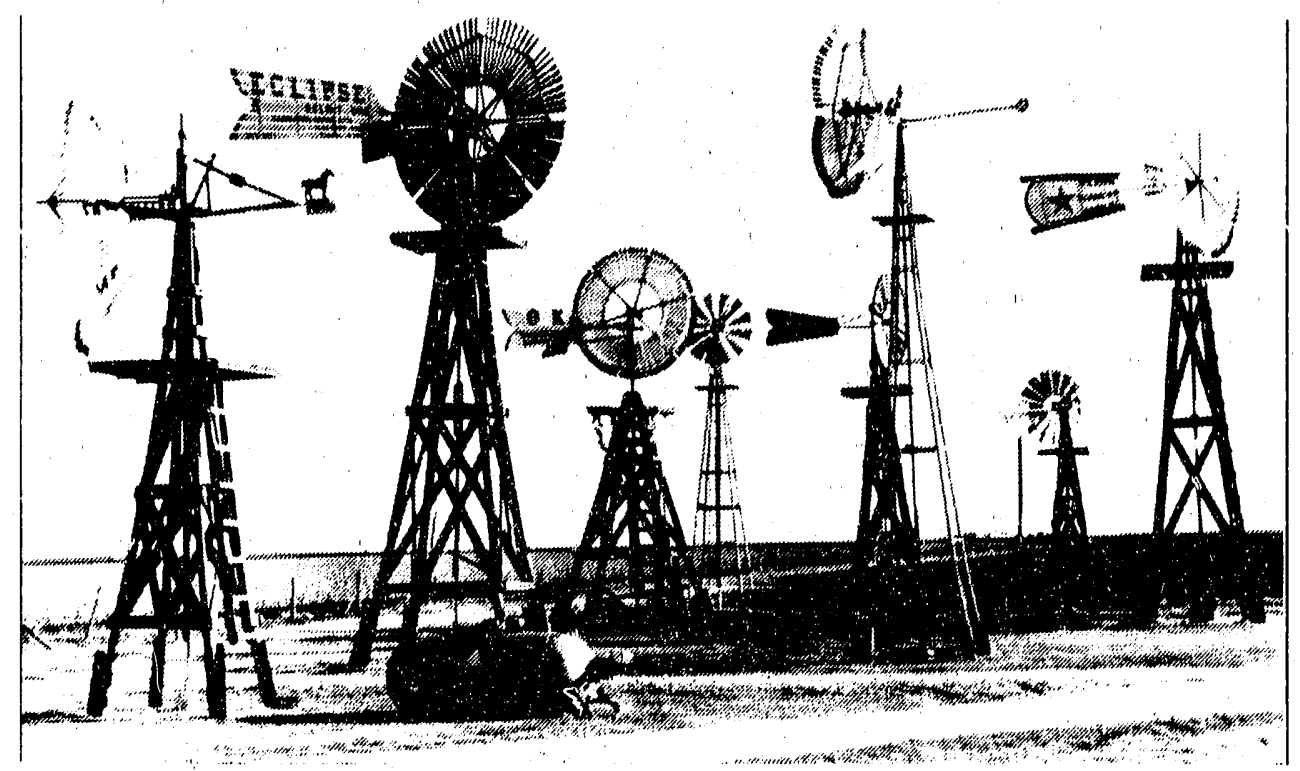

Figure 1-17. Some of the many designs of the American windmill, which was used for pumping water [Baker 1985]. (Reprinted by permission of University of Oklahoma Press; (1985, the University of Oklahoma Press)

perpendicularly to the plane of the wheel provided the winding, and a centrifugal governor changed the blade-setting angle according to the wind speed. Within a few years, the four paddle-type blades were replaced with a large number of thin, wooden blades nailed to wood rims. These blades were grouped in perhaps a dozen sections of a half-dozen blades each; each sectior، was mounted on a hinged casting. This method allowed the groups of blades to be pivoted backward and forward like an umbrella, controller by wind pressure or centrifugal effect, with weignts or springs for reverse action. Rotors of this sort were called sectional wheels and constituted one of the two main styles of American windmills in use throughout the nineteenth century. One variant of the sectional mill did not heve a tail vane, in which case the wheel would become a free-swinging, downwind type, called vaneless sectional. It had a spced control akin to that of the vaned, upwind model.

The second major style of the American windmill was that of the solid wheel, as opposed to the sectional wheel. Blades were mounted together in a single rigid section, and control was effected by moving the whole wheel to some angle to the wind commensurate with the wind speed. The restraint or return motion was effected in a variety of ways. The prototype of the solid whecl was introduced in 1866 by a Reverend Leonard R. Wheeler in Wisconsin and was named the Eclipse. A hinged tail vane on the rear framework of the system could turn from being perpendicular to the wheel to a parallel position for shutting it down. A much smaller fixed vane was mounted on an arm parallel to the whecl, with its tip projecting just beyond the circumference. The drag force on this small vane was such that it tended to turn the wheel out of the wind, thus reducing the effectiveness of the blades in high winds and hence controlling the speed. The restoring force was supplied by a weighted lever or a spring. This form of control remained the most common throughout the era of the American windmill to the present day, but there was considerable variety in the form and use of the side vane. Instead of a side vane, the wheel was mounted somewhat off the tower pivot centerline in a number of designs, its thrust providing the spoiling effect as the wind speed increased.

The number of manufacturers of windmills multiplied rapidly after these beginnings. Stcel blades were introduced in the late 1870 s, but there was considerable scepticism about them at first. There is a reasonable explanation for this, in that wood construction usually 
means more rapid repairs in case of breakage and does not require much machinery, and straightforward carpentry can be applied. Metalworking is more difficult, and repairs sometimes require that replacement parts be ordered, with a consequent increase in machine downtime.

A third major step in the development of the American windmill occurred in 1888 when two men, LaVerne Noyes, an inventor and manufacturer, and Thomas Perry, an engineer with a scientific bent, joined in organizing The Aermotor Company in Chicago. Their facility in designing, manufacturing, and marketing allowed them to sweep the field. By 1900, the Aermotor windmill had captured more than half the market; by the middle of this century, the company claimed to have 800,000 mills in service, more than half of them operating for more than 40 years [Baker 1985]. The Noyes and Perry combination appeared to be a symbiosis of entrepreneur and engineer akin to that of Matthow Boulton and James Watt (albeit in a minor key), achieving both economic and technical success. Perry might also be likened to Smeaton. Nol only did he test an enormous number of existing technical artifacts to instruct himself, and then design and test his own constructions, he also devised a steam-powered whirling arm for testing model wheels, together with instrumentation to measure speeds, temperatures, and pressures.

The Aermotor did not have any major new operating features, but it did have thin, curved, shect-metal blades, properly angled, and supported by steel members offering minimum drag resistance. This resulted in a much lighter wheel with improved acrodynamic perfornance, capable of useful work at both lower and higher wind speeds than wooden wheels. However, its rotational speed was too fast for a reciprocating pump. This necessitated a reduction gear, effected by means of a small pinion on the wheelshaft and a larger gear on a separate crankshaft. This was called a back gear, and it had several advantages, including a high starting torque, a longer pump stroke, and a division of the bearing load between the wheel and the pump. The Aermotor was not the first all-steel mill, but it performed very effectively in terms of efficiency, structural design, and economy of manufacture.

One notable technical problem must be related, however - a problem that surfaces in all engincering designs that include dynamic action - namely, bearings and their lubrication. Two mainstays were the poured babbitt bearing and (perhaps strangely) wood, particularly maple. The latter was used especially to support the pitman, or connecting rod, which converts rotary to reciprocating motion. Nominally "oilless" bronze and graphite came to be used in later years, followed by ball and roller bearings. Lubrication does not sound like a difficult problem, except when the bearings are on top of a tower 6 to $15 \mathrm{~m}$ high, quite open to the weather. Perhaps a weekly chore of climbing the ladder and hanging on while using the oil can or replenishing a container does not appear too risky or arduous for a reasonably active man, but it certainly could be so during months of high winds and icy steps in many parts of the country. Hence, there was a continuous effort to find better ways of reducing the need for attention to lubrication.

One of the most useful automatic lubrication devices was a canister of oil above the bearings, normally closed at the bottom by a spring-loaded valve. A wire from the valve down to the ground could then be pulled to release enough oil to last for a number of days, as judged by the operator. An alternative method was to supply the tower with a hinged center and then tilt it to permit lubrication at ground level. Raising and lowering the top part of the tower was accomplished by using the bottom half as a derrick. A number of hinged towers were used in the last years of the nineteenth century, but they lost favor when they were found to be too susceptible to wind damage. The real solution was introduced by the Elgin Wind Power and Pump Company, which enclosed bearings and other parts requiring lubrication in a casing in the manner of an automobile crankcasc. The gears carried oil up to the shaft and pinion from the case reservoir, with feeds to the other elements of the transmission, and excess oil flowed back to the reservoir. This served all the necessary purposes, keeping dust and water out and eliminating splashing and loss of oil. A sclf-oiling mill also allowed more sophisticated methods of transmission, such as the use of cams or worm wheels. 
The production of multivane windmills was at its peak at about the time of World War I. Although sales were still brisk in the 1920s, there were signs that their heyday might be over. Baker attributes the decline of windmill production and sales that ensued in the 1930s to the Great Dopression, and describes it as a blow from which the industry never recovered [1985]. The economic decline occurred throughout must of the world, and so the very considerable export sales of U.S. companies were likewise reduced. Another, concurrent, reison was that the growing demand for electricity brought power lines into the heartland of the country. So, although times were hard, such funds as were available could be used for electric pumps. Whatever contentment a farmer felt while listening to his windmill working for free was apparently replaced by the ease of pressing a button to turn on the clectricity. Sic transit gloria molini Americani.

\section{From Windmills To Wind Turbines: 1888 To World War II}

\section{The First Wind-Powered Generation of Electricity}

At the end of the nineteenth century, interest developed in using wind power for electrical generation because of the enormous expense of running transmission and distribution lines from central stations to the scattered habitations of the prairies and further west. At that time, it had to be direct-current (DC) power if only because of the varying speed of the windmill, which of course could also cause continual variations in the power delivered (if it was available at all). But the demand was there, and experimental work was carried out in several countries around the turn of the century. Here, we describe two very different pioncering windmill-generators.

The first, shown in the frontispiece, is the Brush windmill, so named for its builder, Charles F. Brush, a Cleveland, Ohio, industrialist in the electrical field [Scientific American 1890; Spera 1977]. In 1888, Brush erected a windmill to supply $12 \mathrm{~kW}$ of DC power for his own large estate, mostly for 350 incandescent lights, of which about 100 were in daily use. The configuration he tised was the post mill. The wheel, with its 144 blades, was $17 \mathrm{~m}$ in diameter on a tower $18 \mathrm{~m}$ high, the latter supported by a central iron post $36 \mathrm{~cm}$ in diarneter extending $2.4 \mathrm{~m}$ into the ground. To provide a steady to relieve strain on the center post in extremely heavy winds, the tower had arms at the four corners carrying casters at their bottom end which had a small clearance with a concentric rail let into the ground. The upwind rotor was a solid-wheel type, with an $18-\mathrm{m}$ by $6-\mathrm{m}$ tail vane and a side vane to turn it out of the wind, like the Wheeler Eclipse. The whole system operated automatically, and maintenance was said to be minimal. It ran for 20 years until the rotor was removed in 1908 .

The Brush windmill was a landmark in the history of the multivane type. In the first place, it was among the largest. built, piacing it in the same category as the 18-m-diameter machines used for flour milling and railroad water pumping. Second, it introduced the high step-up gear ratio (50:1) to windmills, in this case by two belt-and-pulley sets in tandem, to yield a full-load generator speed of $500 \mathrm{rpm}$. Third, it was the first (and highly ambitious) attempt to combine the best-developed structural and aerodynamic windmill technology with newly developing electrical technology. At the same time that it was doing this, it demonstrated that the production of electrical power was unlikely to be a future application of low-speed, multiblade rotors. It could be said that this was a very successful operaeion, but the patient died.

The next important step in the transition from windmills to wind turbine generators was taken by Professor Poul LaCour in Denmark [Juul 1956], again at the turn of the century. LaCour was a scientist who conducted wind turbine research from 1891, the year of his appointment to an experimental station at Askov, until his death in 1907. He put the principles of the new engineering science of aerodynamics into use in the LaCour 
windmill, aind he was one of the first in the world to use a wind tunnel. Figure 1-18(a) shows LaCour's wind tunnel, with a model rotor in position for testing. Because of the high blockage ratio evident in this photograph, the test results were probably not quantitatively correct, but useful relative performance data were apparently obtained.

As we see in Figure 1-18(b), LaCour's rotors still followed the four-bladed, twisted, rectangular pattern of the conventional European windmill, but he appreciated low solidity, leading-edge camber, and low drag. After several years of experimentation, LaCour laid down a set of rules for obtaining optimum rotor performance and succeeded in developing practical wind machines for producing electricity. He designed wind power plants generating 5 to $25 \mathrm{~kW}$ for agricultural and village use, and by 1910 several hundred of these were operating in Denmark. Then along came the diesel, and the beginning of the oscillating fortunes of the windmill, whether for generating electricity or pumping water.

In summary, the transition from windmills supplying mechanical power to wind turbines producing electrical energy took place during the last dozen years of the nineteenth century. Brush's high-solidity post-mill design and LaCour's more practical, low-solidity tower-mill configurations pioneered the stand-alone units that generate DC electricity for charging batteries. As we see in the next section, this was practically the only application of wind-generated electricity until the beginning of World War II.

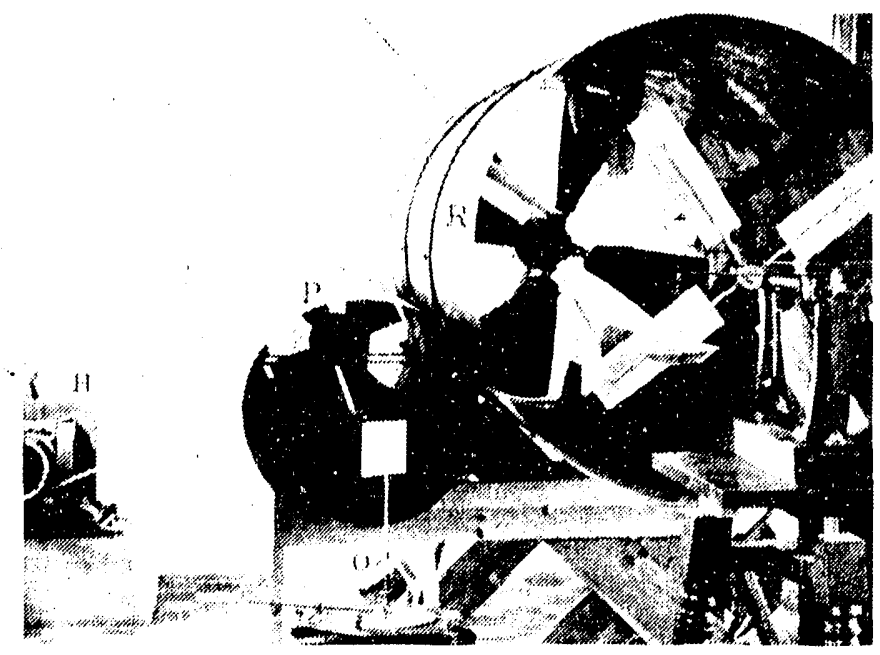

(a)

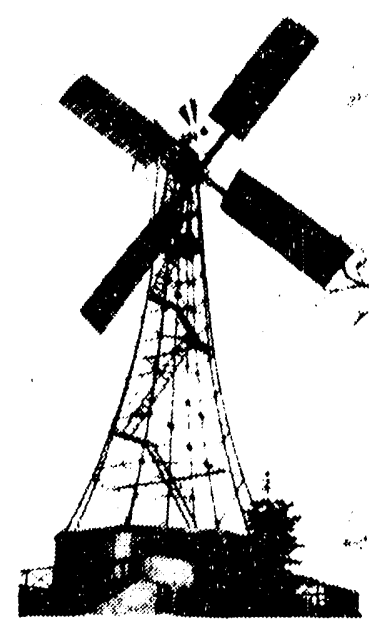

(b)

Figure 1-18. LaCour's adaptation of windmills for generating DC electricity at Askov in Denmark around the turn of the century [Juul 1956]. (a) LaCour's wind tunnel, c. 1895, one of the first in the world. (b) A four-bladed LaCour windmill. (@ 1955, E.W. Golding; 1976, E.\&F.N. Spon Ltd.; reprinted by Halsted Press, John Wiley \& Sons, Inc.)

\section{The Development of Small Wind Turbine Generators}

The advent and development of the airplane in the first decades of the twentieth century gave rise to intense analysis and design studies of the propeller that could immediately be applied to the wind turbine, as we may now properly call it. Professor Albert Betz evolved in clear form the magic value of $16 / 27$ as the ideal maximum utilization factor (or the Betz limit, as it is sometimes called) pertaining to the flux of energy available from the wind [1926]. He was also interested in several other detailed aspects of acrodynamic 
performance, but the times were not auspicious for any considerable undertakings because of the worldwide depression of the 1930s. One notable feature, however, was the introduction in several countries of a new type of fast-running wind turbine having two or three blades with an acrodynamic profile more suitable for generating electricity.

In the United States, the design of Marcellus and Joseph Jacobs could be called the archetypal battery-charging wind generator, it was immensely popular for a quarter of a century [Jacobs 1973]. Figure 1-19 shows the Jacobs Wind Electric power plant. Its development started in 1925, commercial installation began in 1931, and production cnded in 1957. Jacobs' wind generators had a reputation for high performance, minimal maintenance, and excellent structural integrity. A 32-V DC. model delivered up to $2500 \mathrm{~W}$, and a 110)-V DC unit produced up to $3000 \mathrm{~W}$. An irteresting feature of the development period was the selection of a three-bladed rotor. A serious vibrational condition was observed in a two-bladed model during changes in wind direction. As it yawed, the rotor exp rienced a series of jerks produced by changes in gyroscopic inertia about the tower axis each time the blades passed from a vertical to a horizontal position. Three blades, however, provided a smooth transition and solved the vibration problem. (This ciifficulty with two-bladed rotors appears to have been overcome by the use of a teetered hub in these later years.) Note that nearly all Danish wind turbines are still three-bladed, along with some other European types, and these turbines appear to be among the leaders in on-line availability on the West Coast of the United States and elsewhere.

A successful two-bladed, propeller-type turbine for providing direct current was the Wincharger, originally available in sizes from 200 to $1200 \mathrm{~W}$. The $200-\mathrm{W}$ model had a rotor only $1.8 \mathrm{~m}$ in diameter, was much less expensive than the Jacobs machine, and was sold in very large numbers for powering radios and perhaps a few lights on farms and ranches.

An innovative type of wind turbine rotor, the Savonius rotor, was named after its inventor, S. J. Savonius, a Finnish enginecr, and first tested in 1925 [Savonius 1931; Bach 1931]. The inventor's interest had been aroused by the Flettner rotor ship with its large, rotating cylindrical "sails." He was intrigued by the possibility of substituting wind power for the external motor power used to rotate these cylinders on the Flettner ship. His experiments resulted in a rotor with an S-shaped cross section which, in its simplest form, could be constructed by cutting a circular cylinder in half longitudinally and rejoining opposite edges along an axle. Tests did indeed show that his S-rotor could spin a Flettner cylinder with enough power to propel a small boat at speeds up to $15 \mathrm{knots}$, sailing at all angles to the wind.

According to the inventor, the Savonius rotor achieved some popularity in Finland, but it has not prospered commercially as a means for driving an electrical generator. It did have a vogue in the 1960)s and '70s, largely because its design and construction were very simple. It could be made from an oil drum and a piece of pipe, which indeed it was by enthusiastic amateurs in many places around the world. Its other advantages were high starting torque and the ability to accept wind from any direction; its drawbacks were low speed and heavy weight. The Savonius rotor has appeared in more sophisticated forms of cross section, sometimes with three blades to even out the torque variation during each rotor revolution. Its power coefficient is in some doubt, but it would seer 1 that the most reliable maximum value is between 0.18 and 0.23 .

Another innovative rotor design introduced in the early 1930s was a type of verticalaxis turbine invented by F. M. Darricus [1931]. The Darrieus rotor has two or three curved blades attached top and bottom to a central column. This column rotates in upper and lower bearings and transmits torque from the blades to the power train, which is located below the rotor. The upper bearing is supported by a set of guy cables; the column provides the necessary upward force to react the cable tension. The curved shape of the Darrieus turbine blades approximates that which a perfectly flexible member would assume under the action of centripetal forces, with little or no bending stresses along its length. This theoretical curve is called a troposkien, from the Greek for "turning rope," and it is dependent on the rotational speed. 


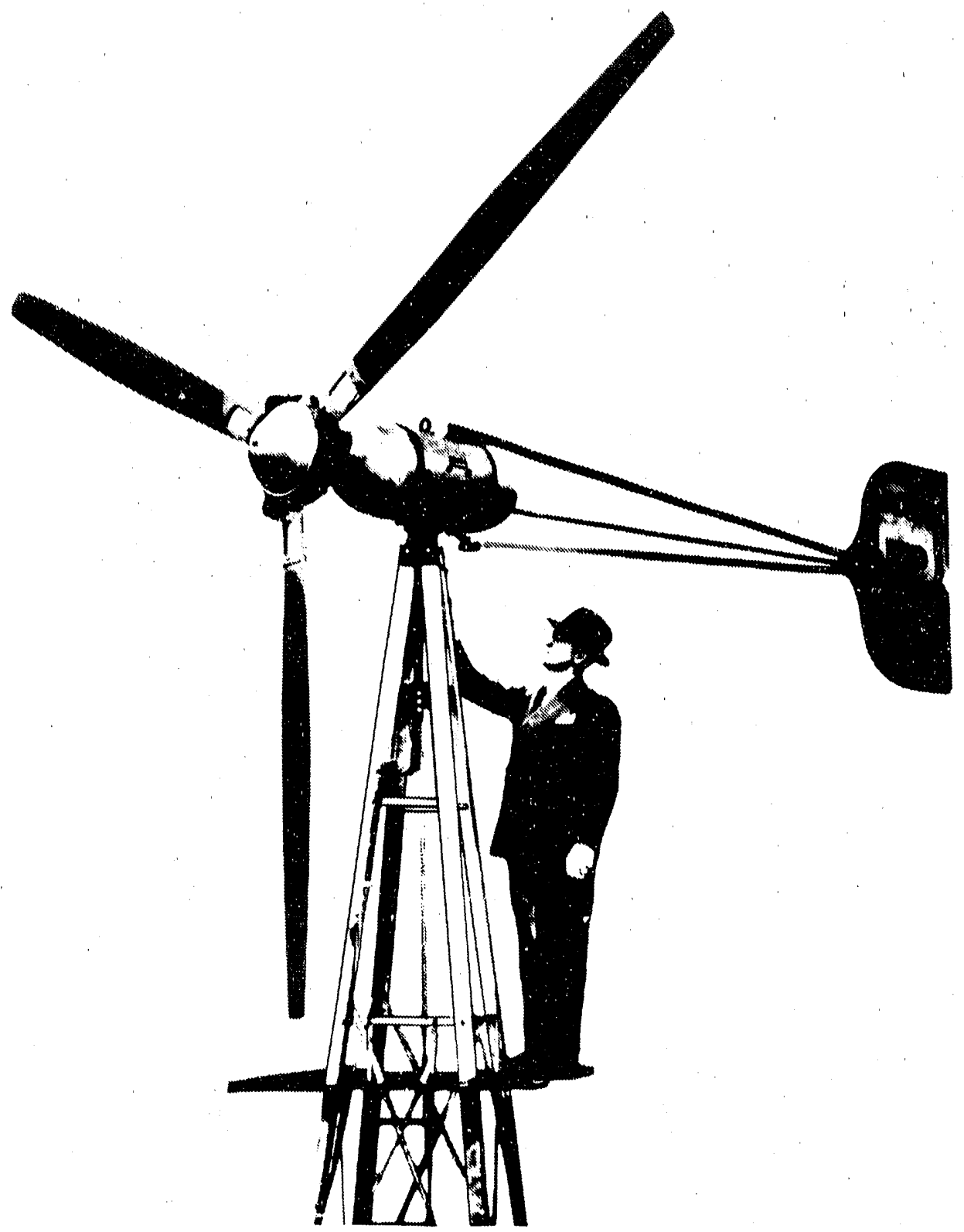

Figure 1-19. A typical stand-alone, battery-charging wind turbine of the 1930s: the Jacobs Wind Electric power plant (Courtesy of Jacobs Wind Electric Co., Inc.)

The two primary advantages of the Darrieus (and VAWTs generally) are its vertical symmetry, which permits it to accept the wind from all directions without yawing, and its location of mechanical and electrical equipment near the ground, where maintenance is easier and weight is not quite so important. After its initial appearance, the Darrieus turbine was generally neglected until it was rediscovered in Canada in the early 1970s and developed further in that country and in the United States.

Thus, the typical wind turbine generator of 1930s had evolved from the pioneering machines of Brush and LaCour into a two- or three-bladed HAWT with the rotor upwind 
of the tower and low solidity, using the same type of tail vane as a water pumper for directional control. Its electrical system usually operated at 12 or $32 \mathrm{~V} \mathrm{DC}$ and utilized leadacid batterics for energy 'storage. Being a stand-alone, direct-current-producing unit, our typical 1930s wind turbine generator usually operated at variable speed with its blades at a fixed pitch angle. Some designs, however, incorporated variable pitch as a means of overspeed control. The Jacobs Wind Electric rotor, for example, allowed centrifugal loads on a flyball governor to pitch its blades. This provided a simple but effective passive pitch control system that feathered the blades with increasing rotor speed.

By the late 1930s, these wind turbines had developed into generally reliable and longlived machines, given reasonable maintenance. They did not, however, have the performance or cost-effectiveness (let alone the capability of producing AC power) to compete with central stations as a source of electricity. This mattered little in outlying areas until the Rural Electrification Act of 1937, enacted as part of the Roosevelt administration's program to bring the nation out of the Great Depression. The REA authorized the construction of new central power plants, many of them hydroclectric, and subsidized the installation of vast electrical distribution systems from these plants with low-interest loans. Unable to compete with central-station power available almost everywhere, the standalone wind turbine, generating low-voltage direct current, became extinct in the United States by the 1940 s, in all but the most remote locations.

The USSR, like the United States, has tremendous areas under cultivation that need electrical power, but the great distances involved make for costly transmission from centralized power plants. Thus, the Russians, too, developed multiblade farm windmills of a simple type with high-torque, low-speed rotors suitable for lifting water with piston pumps. In some cases, the Russian language can be a barrier to their literature, but we have some translations [Fatecv (also spelled Fateyev) 1959, for example] that allow a general picture to emerge which in many ways is similar to that of the West. According to Fateev, wind turbine research had been under government sponsorship in the USSR since the end of World War I and had covered wind tunnel experiments and the establishment of trial grounds for testing complete systems for operational efficiency and mechanical endurance. Modern, high-speed turbines with two or three propeller-type blades have been made in scveral sizes, up to $20 \mathrm{~m}$ in diameter, generating up to $35 \mathrm{~kW}$. Fateev points out that long-term, successful utilization is possible only with good maintenance, and he believes that this was not always available in many communities in Russia (or clsewhere, we might add).

\section{The First Large Wind Power Plants}

Almost parallel with the demise of the small wind turbine was the beginning of interest in larger wind power plants for incorporation into electric utilities. This interest was fostered by an increasing concern about worldwide energy shortages. As carly as 1924, L. Constantin, a French engincer, gave definition to feclings of insecurity with respect to oil supplies; 50 years later, this became a widespread alarm that fossil fuels would soon run out. An excerpt from one of his writings [Constantin 1924] can be translated frecly as follows: "The earth's reserves of fucls, solid and liquid, are rapidly being exhausted, and whatever be the hopes, splendid but distant, that give rise to the study of radioactivity of matter, this suspended threat to our economic life merits the attention of cvery thinking man."

One of the first steps in the development of large-scale wind power plants for electric utility applications was taken in Russia in 1931, with the construction of a 100-kW, 30-m-diameter wind turbine at Balaclava, on the Black Sea; the turbine is shown in Figure 1-20 [Sektorov 1934]. Although its blades had rough surfaces and some of its gears were made of wood, it ran for two years or more and generated some $200,000 \mathrm{kWh}$ in that 


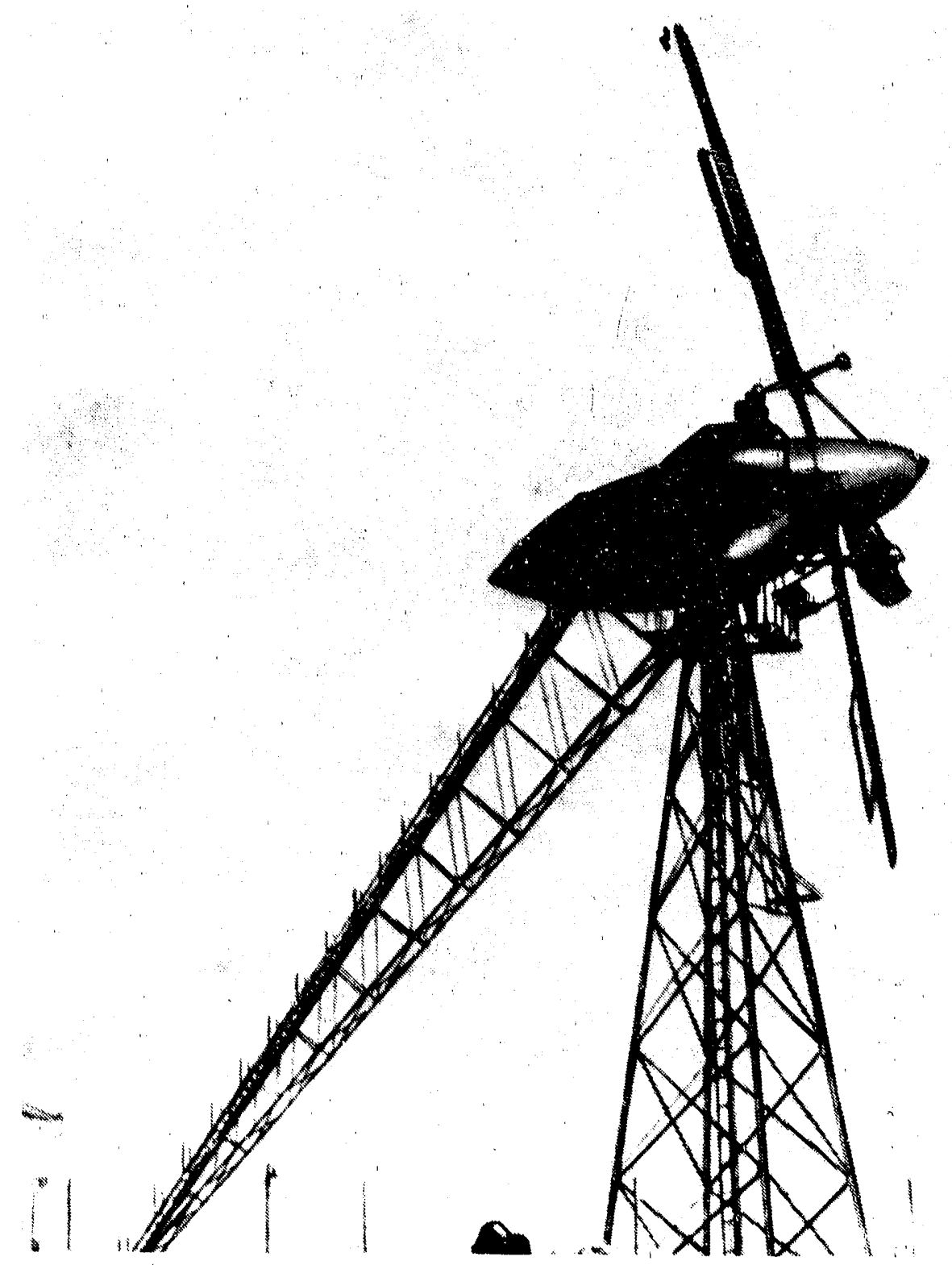

Figure 1-20. Russian wind turbine at Balaclava

time. This machine is historically significant because it is the ( Irliest known example of a wind-driven generator connected to and supplementing an AC utility system.

The last wind turbine discussed in this revicw is the product of a landmark achievement in wind power. This work was conceived and led by Palmer C: Putnam, a brilliant, foreful American engineer who for many years contended that large wind turbines should be utilized to supplement central power plants. In the late 1930s, Putnam interested the S. Morgan Smith Company of York, Pennsylvania, in his plan to build a prototype of a megawatt-scale wind turbine generator using the latest technology. The Smith Company, experienced in the construction of hydroelectric power equipment, agreed to provide financing and manage all phases of the enginecring, construction, and operation. The result of this collaboration was the construction in 1941 of the largest wind turbine up to that time and for almost 40 years afterward. 
The Smith-Putnam wind turbine, shown in Figure 1-21 [Voaden 1943; Putnam 1948; Koeppl 1982], had a two-bladed rotor that swept an area $53.3 \mathrm{~m}$ in diameter. It had a trusstype tower and a rotor axis $33.5 \mathrm{~m}$ above grade. The rotor powered a 1.25-MW synchronous generator through a geared transmission. This configuration was chosen to meet Putnam's goal of producing energy at the lowest possible unit cost and in large enough quantities to be useful to electric utilities. The preliminary design effort was led by Putnam, who recruited a nationwide team of consultants for assistance, including aerodynamicists such as Theodore von Karman at the California Institute of Technology, engineering faculty members at the Massachusetts Institute of Technology, and staff engineers at the General Electric Company.

Technological innovations in the Smith-Putnam wind turbine included full-span active control of blade pitch; the use of individual flapping hinges on the blades to reciuce gyroscopic loads on the shafi (a generic problem with two-bladed rotors on rigid hubs that the Jacohs brothers had experienced earlier); and active yaw control by means of a servomotor turnivis a pinion meshing with a large bull gear between the nacelle and the tower.

The Smith Company organized an experienced industrial team for the final design work, which began in 1939, and for the fabrication of parts, which began in 1940. Blades were built with stainless steel skins to resist corrosion, applying a technology developed for railway passenger cars. After shop assembly and system tests in Cleveland, the machinery and blades were shipped to the site - a hill in Vermont called "Grandpa's

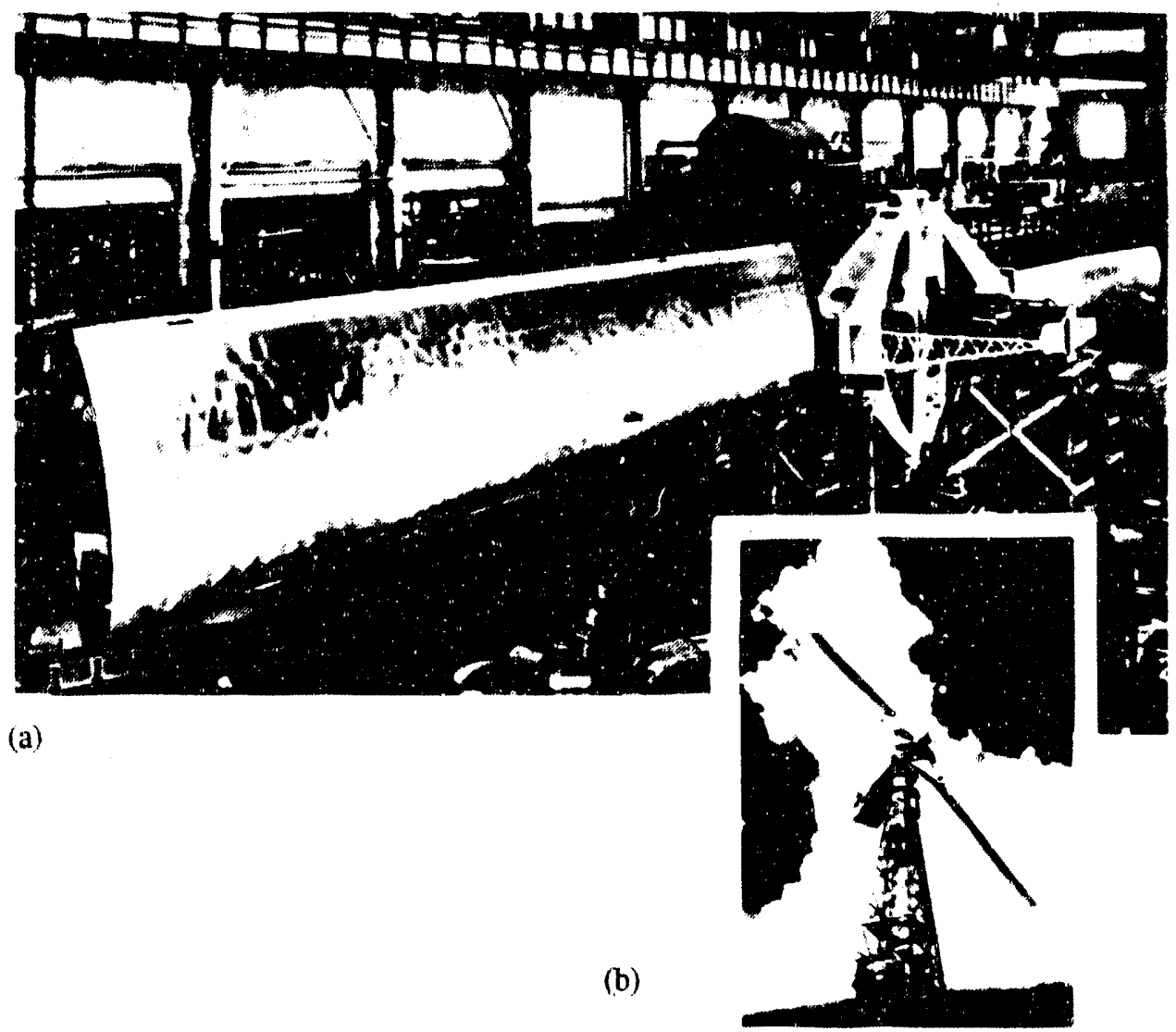

Figure 1-21. The Smith-Putnam wind turbine, c. 1942 - the world's first megawattscale wind power plant. (a) Shop assembly of the $53-\mathrm{m}$ rotor. 'The individually hinged blades have stainless steel skins. (b) Operating atop Grandpa's Knob, near Rutland, Vermont. the power plant transmitted up to $1.25 \mathrm{MW}$ of AC power to the utility system. 
Knob." On October 10, 1941, electricity flowed for the first time from "the windmill on Grandpa's Knob" into the network of the Central Vermont Public Service Corporation.

Several hundred hours of testing proved that the system could operate satisfactorily as a utility power plant. However, a bearing failure in 1943 caused operations to be delayed for two years, because of wartime supply difficulties. It was also discovered that the blade spars were underdesigned at the root, and so reinforcing doubler plates were welded in place. The rotor was then locked in place for the duration of the war, to endure winter storms with little or no maintenance. When operations recommenced in 1945, cracks were discovered in a blade root at a repair weld. Unable to obtain funding for a replacement rotor, the project managers took the risk that the test program could be completed successfully before the cracks propagated to failure. The turbine was run continuously for several weeks with excellent power production, but the risk was too high. In the early hours of March 26, 1945, the faulty blade spar separated at the repair weld. Unfortunately, the S. Morgan Smith Company could not afford to continue the work.

Thus ended one of the great experiments in wind power - one that is outstanding in mechanical engineering. The project was not judged economicaily successful, however, and was abandoned. One reason was that the wind speed was not up to expectations, in spite of the considerable effort that went into selecting the site. Nevertheless, the SmithPutnam wind turbine demonstrated through more than 1000 hours of operation that a megawatt-scale wind power plant - a quantum jump from all previous wind machines could operate in conjunction with a central power station and supply a significant amount of utility-quality $\mathrm{AC}$ power.

As we close this review of the technological development of windmills and early wind turbines - an evolution that stretches back to ancient Persia - we should note that the Smith-Putnam team made two other significant contributions to the technology: they were pioneers in organizing a wind turbine research and development project along the lines of a modern industry/university partnership, and they served as an inspiration for the eventual rebirth of wind power. When the so-called "fuel crisis" of the 1970s caused worldwide shocks that demanded that concrete attention be paid to alternative energy sources, wind power was in the forefront because its technology was already relatively advanced. But we must now end this history of the windmill and move forward to the evolution of modern wind turbines.

\section{References}

Bach, G., June 1931, "Untersuchungen über Savonius-Rotoren und verwandte Strömungsmaschinen," Forsch. Geb. Ingr., 2. Bd./Heft 6, Technische Hochschule, Berlin, pp. 218-231; English translation by C. A. Henkel, 1974, report no. SAND-746018 , Sandia National Laboratories.

Baker, T. L., 1985, A Field Guide to American Windmills, Norman, OK: University of Oklahoma Press.

Bellew, H. W., 1874, From the Indus to the Tigris, London: Trubner and Co.; reprinted in 1977, Royal Book Co., Karachi-3, Pakistan, pp. 239-240.

Betz, A., 1926, Windenergie und Ihre Ausnutzung durch Windmühlen, Gouingen, Germany: Vandenhoeck und Ruprecht.

Boas, M., 1949, "Hero's Pneumatica - A Study of its Transmission and Influence," Isis, 40, pp. 38-48. 
Brangwyn, F., and H. Preston, 1923, Windmills, London: John Lane the Bodley Head; republished in 1975 by Gale Research Co., Detroit, MI, p. 25.

Brown, R. J., 1976, Windmills of England, London: R. Hale, p. 18

Constantin, L., 1924, "Le Vent," La Nature, 52, Pt. 1, pp. 395-400.

Darrieus, F. M., Dec. 1931, "Turbine Having its Rotating Shaft Transverse to the Flow of Current," U.S. Patent No. 1,834,018.

Drachman, A. G., 1961, “Heron's Windmill," Centaurus, 7, pp. 145-151.

Drees, J, M., Spring 1977, "Blade Twist, Droop Snoot, and Forward Spars," Wind Technology Journal, I:1, pp. 10-16; see also "Speculations about the Origin of Sails for Horizontal Axis Turbines," Wind Technology Journal, 1984, 2:1/2, pp. 13-31.

Fateev, E. M. (also cited as Fateyev, Y. M.), 1959, Wind Power Installations. Present Condition and Possible Lines of Development, Moscow; translated by Krammer Associates, 1975, and published as report no. NASA TT-F-16204, Washington, DC: National Aeronautics and Space Administration, $73 \mathrm{pp}$.

Forbes, R. J., ed., 1966, Principal Works of Simon Stevin, Vol. 5, The Works on Engineering of Simon Stevin, E. Crone et al., eds., Amsterdam: Swets and Zeitlinger, plate I.

Forbes, R. J., 1956, "Power," A History of Technology, Vol. II, C. Singer et al., eds., London: Oxford University Press, p. 617.

Freese, S., 1957, Windmills and Millwrighting, London: Cambridge University Press, fig. 3.

Golding, E. W., 1955, The Generation of Electricity by Wind Power, London: E.\&F.N. Spon Lid.; reprinted with an additional chapter by R. I. Harris, 1976, New York: Halsted Press, a Division of John Wiley \& Sons, Inc.

Harris, L. E., 1957, "Land Drainage and Reclamation," A History of Technology, Vol. III, C. Singer et al., eds., London: Oxford University Press, p. 305.

Hedin, S., 1910, Overland to India, Vol. II, London: Macmillan, pp. 135, 292.

Jacobs, M. L., 1973, "Experience with Jacobs Wind-Driven Electric Generating Plant," Proceedings, 1st Wind Energy Conversion Systems Conference, Washington, DC, NSF/RA/N-73-106, pp. 155-158.

Juul, J., 1964, "Design of Wind Power Plants in Denmark," Wind Power, Proceedings of United Nations Conference on New Sources of Energy, Vol. 7, New York: The United Nations, pp. 229-240.

Juul, J., 1956, "Wind Machines," Wind and Solar Energy, Proceedings of New Delhi Symposium, Paris: UNESCO, pp. 56-73.

Kealey, E. J., 1987, Harvesting the Air, Berkeley: University of Californi. Press 
Koeppl; G. W., 1982, Putnam's Power from the Wind, 2nd ed., New York: Van Nostrand Reinhold Co.

Necdham, J., 1965, Science and Civilization in China, Vol. 4, Physics and Physical Technology, Pt. II: Mechanical Engineering, London: Cambridge University Press, pp. 556560.

Notebaart, J. C., 1972, Windmilhlen, Den Haag: Mouton Verlag; see the summary in English, pp. $357 \mathrm{ff}$.

Putnam, G. C., 1948, Power from the Wind, New York: Van Nostrand Reinhold Co.

Savonius, S. J., 1931, "The S-Rotor and Its Applications," Mechanical Engineering, 53(5), pp. 333-338.

Schmidt, W., ed., 1899, Herons von Alexandria, Vol. I, Pneumatica et Automata, Leipzig, Germany: Teubner, pp. xxxix-xl, 203-207.

Scientific American, Dec. 20, 1890, "Mr. Brush's Windmill Dynamo," Vol. LXIII, No. 25, p. 389 (and cover illustrations).

Sektorov, V. R., 1934, "The First Aerodynamic Three-Phase Electric Power Plant in Balaclava," L'Elettrotecritica, 21(23-24), pp. 538-542; translated by Scientific Translation Service, Santa Barbara, CA, NASA TT-F-14933, 13 pp.

Smeaton, J., 1759, "On the Construction and Effects of Windmill Sails," An Experimental Study Concerning the Natural Powers of Water and Wind, Philosophical Transactions of the Royal Society of London, 51, Pt. 1, pp. 138-174; reprinted in Tredgold, T., 1836, Tracts in Hydraulics, 2nd ed., pp. 47-78.

Spera, D. A., 1977, "The Brush Wind Turbine Generator as Described in Scientific American of Dec. 20, 1890," Wind Turbine Structural Dynamics, A Workshop Held at Lewis Research Center, Cleveland, Ohio, November 15-17, 1977, NASA CP-2034, DOE CONF-771148, Cleveland, OH: NASA Lewis Research Center, pp. 275-283.

Stokhuyzen, F., 1965, The Dutch Windmill, Bussum, The Netherlands: van Dishoeck, p. 47.

Torrey, V., 1976, Wind-Catchers, Brattleboro, VT: Stephen Greene Press, pp. 90-91, 148.

Usher, A. P., 1954, A History of Mechanical Inventions, Cambridge, MA: Harvard University Press.

Voaden, G. H., 1943, "The Smith-Putnam Wind Turbine - A Step Forward in AeroElectric Power Research," Turbine Topics, 1(3); reprinted 1981 in NASA CP-2230, DOE CONF-810752, Cleveland, OH: NASA Lewis Research Center, pp. 35-42.

Vowles, H. P., 1930-1931, "An Inquiry into Origins of the Windmill," Transactions of the Newcomen Society of London, XI, pp. 1-14.

Wailes, R., 1957, "Windmills," A History of Technology, Vol. III, C. Singer et al., eds., London: Oxford University Press, p. 107. 
Wailes, R., 1956, “A Note on Windmills," A History of Technology, Vol. II, C. Singer et al., eds., London: Oxford University Press, p. 623.

Wailes, R., 1954, The English Windmill, London: Routledge and Kegan Paul, pp. 92, 150.

White, L., Jr., 1962, Medieval Technulogy and Social Change, London: Oxford University Press, pp. 86-87.

Woodcroft, B., 1851, The Pneumatics of Hero of Alexandria, London: Taylor, Walton, and Maberley, pp. 108-109.

Wulff, H. E., 1966, The Traditional Crafts of Persia, Their Development, Technology, and Influence on Eastern and Western Civilization, Cambridge, MA: M.I.T. Press, pp. 284289.

Additions to the Text

Pg. 3, para. 4, line:

lands), 1977 (England), 1982 (France), 1985 (Belgium), and 1989 ( $w$. Germany)

Pg. 3, para. 4, line 13:

1984 , and 1986, respectively.

Pg. 11, para. 2, line 13; and pg. 13, para. 2, line 10:

(Recently, Holt [1988] has criticized many of Kealey's evidences as unsound. While allowing nine new finds, Holt still fixes the earliest proven dates to be about 1185.)

Pg. 41:

Holt, R., 1988, The Mills of Medieval England, Oxford, England: Basil Blackwell, Ltd., appendix 1. 

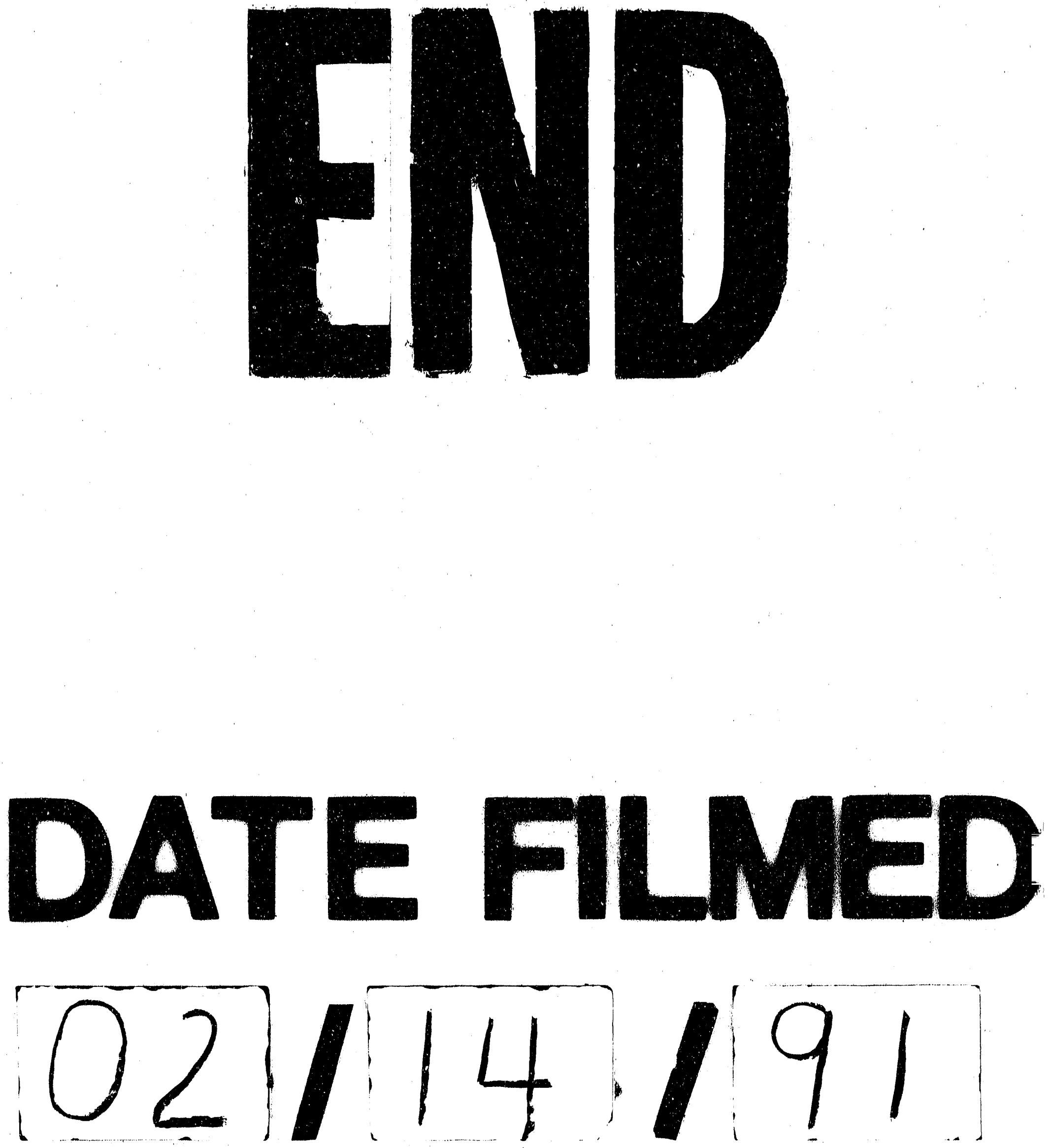
"', 